\title{
Cell sensitivity to oxidative stress is influenced by ferritin autophagy
}

Tino Kurz, Bertil Gustafsson and Ulf Brunk

\section{Linköping University Post Print}

N.B.: When citing this work, cite the original article.

Original Publication:

Tino Kurz, Bertil Gustafsson and Ulf Brunk, Cell sensitivity to oxidative stress is influenced by ferritin autophagy, 2011, FREE RADICAL BIOLOGY AND MEDICINE, (50), 11, 1647 1658.

http://dx.doi.org/10.1016/j.freeradbiomed.2011.03.014

Copyright: Elsevier Science B.V., Amsterdam.

http://www.elsevier.com/

Postprint available at: Linköping University Electronic Press

http://urn.kb.se/resolve?urn=urn:nbn:se:liu:diva-68690 


\title{
Cell sensitivity to oxidative stress is influenced by
}

\section{ferritin autophagy}

\author{
Tino Kurz ${ }^{\text {a,* }}$, Bertil Gustafsson ${ }^{\text {b }}$, and Ulf T. Brunk ${ }^{a}$ \\ ${ }^{a}$ Division of Pharmacology, Faculty of Health Sciences, Linköping University, 58185 \\ Linköping, Sweden, and \\ ${ }^{\mathrm{b}}$ Department of Pathology and Cytology, University Hospital, 58185 Linköping, Sweden.
}

Running title: Ferritin autophagy

*Corresponding author

Tel: +46-10-103-8968

Fax: +46-13-149106

E-mail: tino.kurz@liu.se 


\begin{abstract}
To test the consequences of lysosomal degradation of differently iron-loaded ferritin molecules and to mimic ferritin autophagy under iron-overload and normal conditions, J774 cells were allowed to endocytose heavily iron-loaded ferritin, probably with some adventitious iron, $(\mathrm{Fe}-\mathrm{Ft})$ or iron-free apo-ferritin (apo-Ft). When cells subsequently were exposed to a bolus dose of hydrogen peroxide, apo-Ft prevented lysosomal membrane permeabilization (LMP), while Fe-Ft enhanced LMP. A 4 h pulse of Fe-Ft initially increased oxidative stress-mediated LMP that was reversed after another $3 \mathrm{~h}$ at standard culture conditions, suggesting that lysosomal iron is rapidly exported from lysosomes, with resulting upregulation of apo-ferritin that supposedly is autophagocytosed, thereby preventing LMP by binding intra-lysosomal redox-active iron. The obtained data suggest that upregulation of the stress-protein ferritin is a rapid adaptive mechanism that counteracts LMP and ensuing apoptosis during oxidative stress. In addition, prolonged iron starvation was found to induce apoptotic cell death that, interestingly, was preceded by LMP, suggesting that LMP is a more general phenomenon in apoptosis then so far recognized. The findings provide new insights into ageing and neurodegenerative diseases that are associated with enhanced amounts of cellular iron and show that lysosomal iron-loading sensitizes to oxidative stress.
\end{abstract}

Key words: Apoptosis, autophagy, ferritin, lysosomes, oxidative stress, redox-active iron. 


\section{INTRODUCTION}

Due to its crucial role in the mitochondrial respiratory complexes and a variety of other iron-containing biomolecules, including enzymes needed for cell proliferation, iron is essential for life. However, because of its related capacity to induce homolytic cleavage of hydrogen peroxide, forming the aggressive hydroxyl radical $\left(\mathrm{HO}^{\circ}\right)$ or similarly reactive ironcentered radicals, this transition metal may also be hazardous [1-3]. In turn, these radicals are able to induce peroxidative chain-reactions with generation of organic peroxides, which may decompose to form toxic aldehydes [2].

$$
\begin{aligned}
& \mathrm{Fe}^{2+}+\mathrm{H}_{2} \mathrm{O}_{2} \rightarrow \mathrm{Fe}^{3+}+\mathrm{OH}^{-}+\mathrm{HO}^{\bullet} \\
& \mathrm{LH}+\mathrm{HO}^{\bullet} \rightarrow \mathrm{L}^{\bullet}+\mathrm{H}_{2} \mathrm{O} \\
& \mathrm{L}^{\bullet}+\mathrm{O}_{2} \rightarrow \mathrm{LOO}^{\circ} \\
& \mathrm{LOO}^{\circ}+\mathrm{LH} \rightarrow \mathrm{LOOH}+\mathrm{L}^{\circ}
\end{aligned}
$$

$\mathrm{LOOH} \rightarrow$ aldehydes and other toxic disintegration products

Therefore, cells and organisms need to handle iron with great care. Cellular iron metabolism is schematically summarized in Figure 1. Most iron is hidden within biomolecules, where it is not accessible to hydrogen peroxide. Additionally, iron can be stored for further use in ferritin, a $450 \mathrm{kD}$ protein that binds up to 4,500 atoms of iron [4-10]. Iron is transported in the blood bound to transferrin in a non-redox-active form whilst for transport inside the cell iron requires protein transporters, such as the divalent metal transporter-1 (DMT1, synonymes: Nramp2 or DCT1) [11,12] or the recently identified transient receptor potential protein mucolipin 1 (synonymes: TRPML1 or MCOLN1) [13]. Presently, it is unknown whether iron undergoing intracellular transport is partly in a redoxactive form. Iron uptake is strictly controlled and kept at a minimum [14,15], except in 
pathological iron-overload conditions. Cells absorb iron from their environment, mainly during proliferation, making tumor cells particularly sensitive to iron-chelators [16], while non-dividing cells mainly rely on efficient turnover and reutilization of this metal [17]. Ferritin can also be taken up by a recently found ferritin receptor called Scara5 [18] and, interestingly, the $\mathrm{H}$ subunit of circulating ferritin even by the transferrin receptor-1 [19].

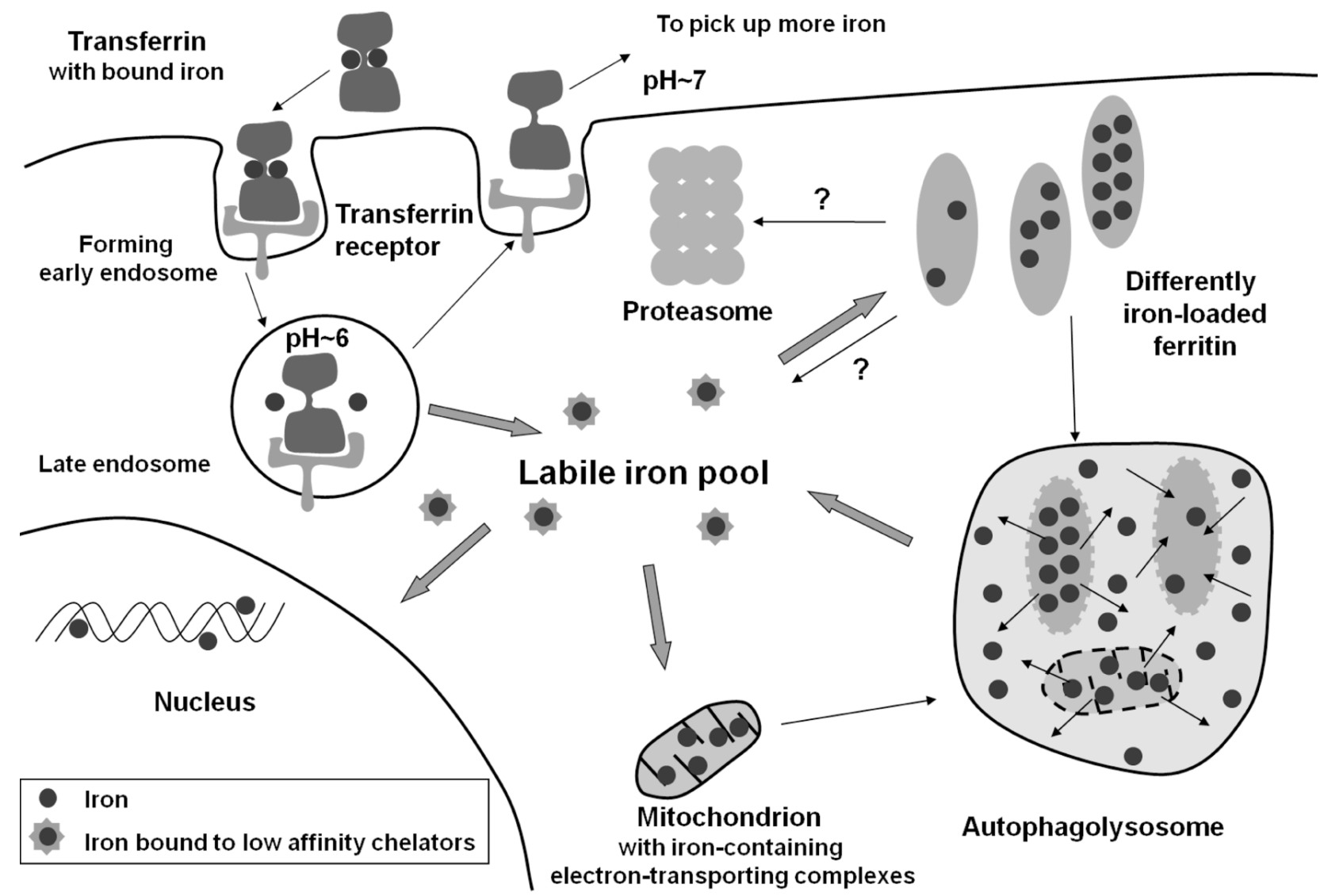

Figure 1. Schematic illustration of cellular iron-uptake, intracellular transport, and turnover of iron-containing structures. Although autophagy of ferritin is now well proven as the major mechanism behind release of iron from ferritin, it has been suggested that iron may also be released directly from ferritin in the cytosol or by proteasomal degradation.

Ultimately, organisms accumulate iron over time, especially in the liver and in postmitotic cells, such as neurons, cardiomyocytes and retinal pigment epithelial cells [20-23]. The implications of this phenomenon are not yet fully understood, but may contribute to a number of age-related diseases, such as atherosclerosis, age-related macular degeneration and 
neurodegenerative disorders, for example, Parkinson's, Alzheimer's and Friedreich's diseases [24-28], perhaps by making cells more sensitive to oxidation.

Iron loading of ferritin takes place through symmetrical channels and is supposed to be an autonomous process in response to the concentration of cytosolic iron $[9,10]$. When iron is required for anabolic purposes, it is released from ferritin, usually in combination with an upregulation of transferrin receptors, increased receptor-mediated iron uptake, and downregulation of ferritin [15]. Iron release from ferritin is controversial. One hypothesis postulates it to be liberated directly in the cytosol under the influence of a feedback mechanism $[10,29,30]$. Another hypothesis that recently has gained strong support suggests a lysosomal pathway involving ferritin autophagy followed by degradation inside the lysosomal compartment and transfer of the liberated iron to the cytosol [8,31-42]. Finally, ferritin degradation by proteasomes has been suggested, as well as a combination of lysosomal and proteasomal degradation $[10,42,43]$. The details behind the relocation of iron from lysosomes to the cytosol following autophagic degradation of ferruginous macromolecules are not wellknown, but may be akin to those involved in the transport of iron from late endosomes to the cytosol (see above).

Knowledge about the regulatory mechanisms behind autophagy has recently been substantially expanded. The evolutionary preserved ATG gene family was initially identified in yeast and later found to control autophagy in a highly specific manner [44-46]. Autophagy was previously considered a mainly adaptive catabolic mechanism, allowing cells to rid themselves of damaged structures, or permitting them to survive periods of starvation by degrading their own non-essential parts. Now it is recognized that autophagy is also the major mechanism behind the normal turnover of cellular constituents. All organelles, and many proteins, especially long-lived ones, are degraded by autophagy and the end products are transported to the cytosol to be re-utililized by the anabolic machinery [47-49]. Many 
autophagocytosed macromolecules contain iron that, therefore, is released in low mass form inside the lysosomal compartment. As a result, lysosomes that are, or just have been, engaged in autophagic degradation are rich in low mass iron and vulnerable to oxidative stress. Resting lysosomes may contain little or no iron and, thus, remain indifferent to such stress $[20,39,40,50]$.

The simultaneous presence of redox-active iron and hydrogen peroxide (diffusing in from the cytosol) inside the acidic and reducing lysosomal environment, inevitably gives rise to some degree of Fenton-type chemistry. This is the background to the peroxidative formation of the age pigment lipofuscin that mainly accumulates in postmitotic cells that cannot dilute it by division. Lipofuscin is also to some degree found in cells that were heavily engaged in reparative autophagy, e.g. following x-irradiation or virus infection (for a review see refs. [51,52]). During substantial oxidative stress, resulting Fenton-type reactions inside iron-rich lysosomes may be so violent that the integrity of the surrounding membranes is breached, allowing relocation of lysosomal contents to the cytosol. This may result in apoptosis or necrosis depending on the magnitude of lysosomal membrane permeabilization (LMP) $[22,39,40,53-58]$.

It is often observed that oxidative stress results in a large variation of LMP between and within cells [58]. The reason for this is probably, as pointed out above, that some lysosomes are involved in autophagic degradation of ferruginous material and rich in iron [22], while others are resting.

Thus, the presence of lysosomal redox-active iron makes cells sensitive to oxidative stress. However, most probably evolution has found ways to minimize the danger, for example by restricting formation of hydrogen peroxide, keeping intralysosomal iron in a non-redox-active form, or rapidly transporting newly released low mass iron away from the lysosomal compartment. 
We know that long-lived animals usually have a lower metabolic rate compared to shortlived ones and, more importantly, also a reduced leak of electrons from their mitochondrial complexes and the intermediate electron transporters. This is most obvious when the life spans are compared for animals with the same metabolic rate, such as mice and rats $v s$ bats, and birds $[59,60]$. However, when it comes to the regulation of iron transport from lysosomes to the cytosol, the redox-activity of iron under transport, or mechanisms that possibly may influence the ratio of redox-active to non-redox-active iron in the lysosomes, we are almost completely ignorant. The main location for synthesis of iron-containing complexes, such as heme and iron-sulfur clusters, is in the mitochondria, to which iron is perhaps transported following fusion with late endosomes/lysosomes [61] or, more probably, from a cytosolic pool of low mass iron of unknown redox-activity (see Figure 1).

In this study, we tested the hypothesis that autophagy of ferritin, depending on its degree of iron saturation, either stabilizes or destabilizes lysosomes against oxidative stress. Normal autophagy of differently iron-saturated ferritins was mimicked by allowing cultured macrophage-like J774 cells to endocytose apo-ferritin, or heavily iron-loaded ferritin with adsorbed iron. Cells were then exposed to a bolus dose of hydrogen peroxide, and the resulting change of LMP and its consequences were assayed.

We also studied the influence of iron-starvation on the induction of ferritin autophagy by exposing J774 and HeLa cells to two different iron chelators, salicylaldehyde isonicotinoyl hydrazone (SIH) and calcein (added in the form of calcein-AM). We found that lysosomal, and thereby also cellular, sensitivity to oxidative stress is related to the iron content of ferritin under degradation. We hypothesize that following autophagy non-Fe-saturated ferritin may temporarily (before complete degradation) bind iron with consequent depression of intralysosomal redox-active iron, while heavily iron-loaded ferritin with adsorbed iron would have the opposite effect. Additionally, we found that lysosomal iron is rapidly relocated to the 
cytosol, and that iron-starvation induces programmed cell death that, interestingly, is preceded by LMP. 


\section{MATERIALS AND METHODS}

\section{Chemicals}

Dulbecco's Modified Eagle's Medium (DMEM), penicillin and streptomycin were from Invitrogen (Paisley, UK). Fetal bovine serum (FBS) was from PAA (Pasching, Austria). Silver-lactate, propidium iodide, Glutaraldehyde, Fe-saturated horse spleen ferritin (96701), horse spleen apo-ferritin (A3641), protease inhibitor cocktail (P8340), pepstatin A (P5318), E64d (E8640), acridine orange base (AO), ammonium sulfide and hydroquinone were from Sigma (St. Louis, Missouri, USA). Tris-HCl polyacrylamide gels (15\%) and milk powder were from Bio-Rad (Hercules, California, USA). Immobilon-P PVDF membranes (pore size $0.45 \mu \mathrm{m})$ were from Millipore (Temecula, California, USA). Tetramethylrhodamine (TMRE), Lysotracker Red, calcein and calcein-AM were from Molecular Probes (Eugene, Oregon, USA). Polyclonal rabbit $\alpha$-human ferritin antibodies (865077) were from MP Biomedicals (Solon, Ohio, USA), rabbit polyclonal antibodies against LC3 (PD014) were from MBL (Woburn, Massachusetts, USA), GAPDH antibodies (IMG-5143A) were from Imgenex (San Diego, California, USA), anti-rabbit IgG conjugated to HRP (sc-2004) were from Santa Cruz Biotechnology (Santa Cruz, California, USA). Western Lightning Chemiluminescence Reagent Plus was from Perkin Elmer (Waltham, Massachusetts, USA). Salicylaldehyde isonicotinoyl hydrazone (SIH) was a kind gift from Professor Des Richardson, University of Sydney, Australia.

Cell cultures, induction of oxidative stress, and assessment of lysosomal membrane permeability $(L M P)$

Murine macrophage-like J774 cells (ATCC) and HeLa cells (a kind gift from Dr. Arne Holmgren, Karolinska Institute, Stockholm) were grown in DMEM supplemented with 10\% FBS, $2 \mathrm{mM}$ L-glutamine, $100 \mathrm{IU} / \mathrm{ml}$ penicillin and $100 \mu \mathrm{g} / \mathrm{ml}$ streptomycin, at $37^{\circ} \mathrm{C}$ in 
humidified air with $5 \% \mathrm{CO}_{2}$. The cells were split twice a week, plated in 6-well plates at a concentration of $10^{6}$ cells/well (with or without cover-slips) and typically subjected to oxidative stress (or not) $24 \mathrm{~h}$ later.

Suitable concentrations and exposure times (in relation to cell density) for hydrogen peroxide, iron-complexes and iron chelators were established in preliminary studies. In the final experiments, cells were exposed for $4 \mathrm{~h}$ to fresh complete medium with or without $1 \mu \mathrm{M}$ apo-Ft or Fe-Ft or $30 \mu \mathrm{M}$ of a hydrated iron-phosphate complex, obtained by adding $\mathrm{FeCl}_{3}$ to complete culture medium (during the $4 \mathrm{~h}$ the ferritins and the iron-phosphate complex are endocytosed and transported into the lysosomal compartment). The cells were then exposed to a 30 min period of oxidative stress (a bolus dose of initially $100 \mu \mathrm{M}$ hydrogen peroxide in 2 $\mathrm{ml} \mathrm{HBSS}$ at $37^{\circ} \mathrm{C}$, which declines to $<20 \mu \mathrm{M}$ at the end of the exposure period). Cells were analyzed for LMP using the AO-uptake method (see below) 6-7 h later. It needs to be pointed out that in the case of oxidative stress (such as cellular exposure to hydrogen peroxide), lysosomal redox-active iron produces hydroxyl radicals that may induce peroxidation of the lysosomal membrane. This, however, is not an instantaneous process and only after several hours does membrane fragmentation and consequent LMP become obvious. By then, however, there may be no ongoing oxidation at all and, therefore, the effect of an oxidative situation can be assayed only after a considerable delay [62].

In other experiments, cells were exposed as above, while early LMP was assessed by the more sensitive AO relocation method (see below) immediately after end of the oxidative stress period.

Alterations of the mitochondrial membrane potential $\left(\Delta \Psi_{m}\right)$ were registered for up to $8 \mathrm{~h}$ following the end of the oxidative stress period using the TMRE method (see below) [63].

To assess transport of iron liberated inside lysosomes following degradation of endocytosed Fe-FT, and the effect of upregulation and ensuing autophagy of apo-Ft, cells 
were exposed to Fe-FT for $4 \mathrm{~h}$, rinsed and then kept at standard culture conditions for another $30 \mathrm{~min}$ to $7 \mathrm{~h}$ before being subjected to oxidative stress (as above). LMP was assayed by the AO uptake method as described below.

In order to evaluate the effect of endocytic uptake of apo-Ft or Fe-Ft on lysosomal sensitivity to oxidative stress, cells that were exposed to apo-Ft or Fe-FT, respectively, were compared to cells that were protected by $50 \mu \mathrm{M}$ of the lipophilic iron-chelator salicylaldehyde isonicotinoyl hydrazone $(\mathrm{SIH})$ during the oxidative stress event. As described before, SIHprotection during oxidative stress almost completely prevents moderate oxidative stressinduced damage [63].

To test if enhanced LMP is involved in the form of apoptosis that is a consequence of prolonged iron starvation, cells were exposed to $50 \mu \mathrm{M} \mathrm{SIH}$ for up to $7 \mathrm{~h}$ (when morphologic alterations typical of apoptosis were found to be present) and then assayed with the AO uptake method.

\section{LMP assays}

Acridine orange (AO) is a metachromatic fluorophore and a lysosomotropic weak base $(\mathrm{pKa} \sim 10)$ that becomes charged $\left(\mathrm{AOH}^{+}\right)$and retained by proton trapping within the lysosomal compartment ( $\mathrm{pH}$ 4.0-5.5). When cells then are excited by blue light, lysosomes emit intense red fluorescence (high AO-concentration), while the cytosol and nuclei, due to binding of some $\mathrm{AO}$ to proteins and DNA, show weak diffuse green fluorescence (low AOconcentration). When cells are excited with green light, only moderately intense red lysosomal fluorescence is observed.

The AO-relocation method [40,50,53,64-66] requiring blue light activation, is based on the assessment of increased cytosolic green fluorescence secondary to lysosomal rupture with 
relocation to the cytosol of $\mathrm{AO}$ as well as of protons. In the cytosol, where AO turns less concentrated, its fluorescence shifts from red to green.

The AO-uptake method, involving activation with either blue or green light, measures red lysosomal fluorescence. Since most photomultipliers are much more sensitive to photons from green than from red light, the AO-relocation method is the more sensitive one. However, it can be applied only shortly following initiation of LMP, the reason being that ensuing relocation of lytic lysosomal enzymes and redox-active iron results in plasma membrane damage and further AO-leakage to the medium. In practice, it usually means that the relocation method can be applied no later than 30-60 minutes following induction of LMP.

The AO-relocation technique $[39,40,53,64,66]$ was thus used to evaluate early and minor LMP. For this assay, cells were pre-loaded with AO $(10 \mu \mathrm{g} / \mathrm{ml})$ for $15 \mathrm{~min}$ (in the dark) in complete culture medium, rinsed with culture medium and kept under standard culture conditions for another $15 \mathrm{~min}$ before being exposed to oxidative stress. Cells were then scraped off and assayed by flow cytofluorometry. The increase in green cytoplasmic fluorescence was measured in the $\mathrm{FL}_{1}$ channel using a Becton-Dickinson FACScan equipped with a $488 \mathrm{~nm}$ argon laser. CellQuest software was used for data acquisition and analyses.

Advanced LMP was measured by the AO-uptake method. Cells were AO-stained $6 \mathrm{~h}$ following end of the oxidative stress period, scraped, and evaluated by flow cytofluorometry ( $\mathrm{FL}_{3}$ channel) for red fluorescence. As explained above, a rather long delay between end of the oxidative stress and exposure to AO is needed in order to allow LMP to become manifest. Cells with a reduced number of intact AO-accumulating lysosomes (reduced red fluorescence) were termed 'pale' cells. 


\section{Cytochemical evaluation of lysosomal low mass iron}

For the evaluation of cellular low mass iron, we used the modified (high $\mathrm{pH}$; high $\mathrm{S}^{2-}$ ) sulfide-silver method (SSM) [50], which is based on Timm's technique for cytochemical detection of a variety of heavy metals [67]. Cells $\left(10^{6} \mathrm{~J} 774\right.$ or $\left.3 \times 10^{5} \mathrm{HeLa}\right)$ were grown on coverslips and exposed (or not) for $4 \mathrm{~h}$ to $0.1 \mu \mathrm{M} \mathrm{Fe}-\mathrm{Ft}$ or to $30 \mu \mathrm{M}$ of the above described hydrated iron phosphate complex that is non-solvable at $\mathrm{pH}$ 7. Cells were then briefly rinsed in PBS $\left(22^{\circ} \mathrm{C}\right)$ and kept under standard culture conditions for another $1.5 \mathrm{~h}$ prior to fixation with $2 \%$ glutaraldehyde in $0.1 \mathrm{M} \mathrm{Na-cacodylate} \mathrm{buffer} \mathrm{with} 0.1 \mathrm{M}$ sucrose (pH 7.2) for $2 \mathrm{~h}$ at $22^{\circ} \mathrm{C}$. The fixation was followed by short rinses (x 5) in glass-distilled water at $22^{\circ} \mathrm{C}$. Cells were then sulfidated at $\mathrm{pH} \approx 9$ with $1 \%(\mathrm{w} / \mathrm{v})$ ammonium sulfide in $70 \%(\mathrm{v} / \mathrm{v})$ ethanol for 15 min. Following careful rinsing in glass-distilled water for 10 min at $22^{\circ} \mathrm{C}$, development was performed using a physical, colloid-protected developer containing silver-lactate and hydroquinone (the method is autocatalytic and the precipitation of metallic silver on the FeS core is dependent on time and the amount of initiating FeS). The reaction was performed in the dark at $26^{\circ} \mathrm{C}$ for various periods of time (30-60 min). Following dehydration in a graded series of ethanol solutions and mounting in Canada balsam (to prevent oxidation of black atomic silver to white silver-oxide that may happen following mounting in synthetic mounting media without added anti-oxidants), the cells were examined and photographed, using transmitted light, under an Axioscope microscope (Zeiss) connected to a Zeiss ZVS-47E digital camera. Easy Image Measurement 2000 software (version 2.3, Bergström Instruments AB, Solna, Sweden) was used for image acquisition.

\section{Apoptosis assays}

The Nicoletti DNA fragmentation assay is based on propidium iodide (PI) staining of nuclear DNA and was performed essentially as previously described [68]. Cell pellets from 
individual dishes were re-suspended in $1.5 \mathrm{ml}$ of a hypotonic and membrane-disrupting solution of PI (50 $\mu \mathrm{g} / \mathrm{ml}$ in $0.1 \%$ sodium citrate with $0.1 \%$ Triton $\mathrm{X}-100)$ and kept in the dark overnight at $4^{\circ} \mathrm{C}$. Then the PI-induced red fluorescence of suspended individual nuclei or apoptotic nuclear fragments was measured by flow cytofluorometry using the $\mathrm{FL}_{3}$ channel. Nuclei with partially degraded DNA and nuclear fragments were counted and their frequency was expressed as a percentage of the total number of particles analyzed $(10,000)$.

Cell cultures were also followed by phase contrast microscopy. The numbers of apoptotic (membrane blebbing, nuclear condensation/fragmentation, formation of apoptotic bodies) and necrotic cells (cellular and nuclear swelling and lysis) were registered.

\section{Mitochondrial membrane potential assay}

Mitochondrial membrane potential $\left(\Psi_{m}\right)$ was measured by flow cytofluorometry as described [63], using the cationic and lipophilic dye tetramethylrhodamine ethyl ester (TMRE) that accumulates in the mitochondrial matrix. Decreased $\Psi_{m}$ is indicated by a reduction of the TMRE-induced red fluorescence. At different time points (30 min - $8 \mathrm{~h}$ ) following the end of the oxidative stress (see above), cells were incubated with TMRE in complete culture medium $\left(100 \mathrm{nM} ; 15 \mathrm{~min} ; 37^{\circ} \mathrm{C}\right)$. Red fluorescence $\left(\mathrm{FL}_{3}\right.$ channel) was recorded in a log scale and analyzed using the CellQuest software. Cells with reduced red fluorescence were gated.

\section{Assessment of ferritin upregulation by western blotting}

J774 cells were pulse-exposed to Fe-FT for $4 \mathrm{~h}$ and then kept at standard conditions for another $4 \mathrm{~h}$ before they were harvested for immunodetection of ferritin. Cells were lysed in 50 mM Tris-HCl, $\mathrm{pH}$ 7.6, $250 \mathrm{mM} \mathrm{NaCl,} \mathrm{0.5 \%} \mathrm{Triton} \mathrm{X-100,} \mathrm{2mM} \mathrm{EDTA,} \mathrm{20 \%} \mathrm{Glycerin,} 1 \mathrm{mM}$ PMSF, 1\% Protease inhibitor cocktail, 0.2 mM DTT. Protein $(50 \mu \mathrm{g})$ was applied in Laemmli 
buffer onto a $15 \%$ Tris- $\mathrm{HCl}$ gel, separated in a denaturing polyacrylamide gel electrophoresis and transferred onto an Immobilon-P PVDF membrane (pore size $0.45 \mu \mathrm{m}$ ). Following blocking in $5 \%$ milk in TBS (10 mM Tris base, $150 \mathrm{mM} \mathrm{NaCl}, \mathrm{pH} 8.0)$ with $0.1 \%$ Tween-20 (TBS-T) and washing in TBS-T, ferritin was detected using polyclonal rabbit $\alpha$-human ferritin antibodies $\left(1: 500(18.5 \mu \mathrm{g} / \mathrm{ml})\right.$ in TBS-T with $0.1 \%$ milk over night at $4^{\circ} \mathrm{C}$ and visualized using anti-rabbit IgG conjugated to $\operatorname{HRP}(1: 1,000(0.4 \mu \mathrm{g} / \mathrm{ml})$ in TBS-T with $0.1 \%$ milk for 1 $\mathrm{h}$ at ambient temperature. Western Lightning Chemiluminescence Reagent Plus was used as a substrate for HRP, and chemiluminescence was detected using a luminescent image analyzer LAS-1000 (Fujifilm). As a loading control, visualization of GAPDH $(1: 1,000(0.5 \mu \mathrm{g} / \mathrm{ml})$ in TBS-T with $0.1 \%$ milk for $1 \mathrm{~h}$ at ambient temperature) was used.

Assessment of autophagy by immunodetection of LC3.

HeLa cells were exposed to calcein-induced iron-starvation for up to $15 \mathrm{~h}$. In order to protect against possible autophagic degradation of the LC3-II protein, cells were in some experiments initially exposed for $4 \mathrm{~h}$ to a combination of $10 \mu \mathrm{g} / \mathrm{ml}$ each of pepstatin A (an inhibitor of cathepsins D and E) and E64d (an inhibitor of cathepsins B, H and L) [69]. Adherent cells were collected and lysed at $4^{\circ} \mathrm{C}$ in $50 \mathrm{mM}$ Tris- $\mathrm{HCl}, \mathrm{pH} 7.2,0.1 \%$ Triton-X100, 10\% glycerol, $1 \mathrm{mM}$ PMSF and 1\% Protease inhibitor cocktail. The western blotting was done as described for ferritin above. The LC3 proteins (band I and II) were detected using rabbit polyclonal antibodies (1:1,000 in TBS-T with $0.1 \%$ milk for $3 \mathrm{~h}$ at ambient temperature) and visualized using anti-rabbit IgG conjugated to HRP $(0.4 \mu \mathrm{g} / \mathrm{ml}$ in TBS-T with $0.1 \%$ milk) for $1 \mathrm{~h}$ at ambient temperature. 


\section{Estimation of cytosolic autophagy using calcein-AM}

Cells $\left(3 \times 10^{5} \mathrm{HeLa}\right)$, grown on coverslips, were exposed for 15 min to calcein by adding calcein-AM (200 nM) in complete medium, rinsed in culture medium, and then kept at standard culture conditions for up to $15 \mathrm{~h}$. During this period, the distribution and magnitude of calcein fluorescence was studied and repeatedly photographed using a Nikon Eclipse C1 laser scanning confocal microscope equipped with a $488 \mathrm{~nm}$ laser and the Nikon EZ-C1 V2.30 software for image acquisition. Cells were documented directly or following a brief exposure to $\mathrm{SIH}(100 \mu \mathrm{M})$ to certify that by time diminishing calcein-induced fluorescence was not a result of iron-mediated quenching.

The lipophilic calcein-AM ester passes the plasma membrane, but it is then immediately split by cytosolic nonspecific esterases. One of the reaction products, calcein, is a hydrophilic, fluorochromic alcohol that does not pass membranes. At neutral $\mathrm{pH}$, but not at the lysosomal $\mathrm{pH}$ of about 5, calcein fluorescence is significantly quenched by low mass iron [70]. When parts of the calcein-containing cytosol are autophagocytosed, its fluorescence is substantially increased (calcein is retained and concentrated within the lysosomal compartment that counteracts the less intense calcein fluorescence at the low lysosomal pH) [70]. Moreover, at lysosomal $\mathrm{pH}$ calcein does not bind iron [70] and, consequently, calcein fluorescence is not iron-quenched in the lysosomal compartment, although plenty of iron may be present. A gradual appearance of granules with bright calcein-mediated fluorescence, paralleled by a disappearence of cytosolic fluorescence will thus reflect ongoing autophagy of the cytosol, including its ferritin.

The fluorescence and iron-quenching properties of calcein $(50 \mathrm{nM}$ in $150 \mathrm{mM}$ acetate or HEPES buffers - pH 5.0 and 7.4, respectively) was assayed in stirred $2 \mathrm{ml}$ cuvettes using a Hitachi F-7000 spectrofluorometer operated at $\lambda_{\mathrm{ex}} 488 \mathrm{~nm}$ and $\lambda_{\mathrm{em}} 518 \mathrm{~nm}$. Ferrous iron (obtained by mixing equal amounts of dissolved $\mathrm{FeCl}_{3}$ and ascorbic acid) was applied to 
increase the final iron concentration in steps. To de-quench calcein fluorescence, the iron chelator SIH was added in excess.

\section{Statistical analysis}

Results are given as means \pm SD. Statistical comparisons were made using analysis of variance (ANOVA), whereby pair-wise multiple comparisons were made using Tukey's adjustment. For comparison of two means, Student's t test was used. $\mathrm{p}<0.05(*), \mathrm{p}<0.01$ $(* *), \mathrm{p}<0.001(* * *)$. 


\section{RESULTS}

\section{Lysosomes are rich in low mass iron}

To demonstrate lysosomal iron and to study the effect of endocytotic uptake of iron-rich compounds, we employed the sensitive, autocatalytic, cytochemical sulfide-silver method (SSM), which demonstrates a variety of heavy metals [50]. The SSM is considered specific for iron since in most cells iron is the only heavy metal that normally is present in low mass form to any significant degree; except for in a few particularly Zn-rich cell types, such as $\beta$ cells, prostatic epithelial cells, and certain neurons. When J774 and HeLa cells were subjected to the SSM a granular, lysosomal-type staining was evident (see Figure 2, panels A and B). Staining density varied, indicating large differences in the amount of lysosomal iron between individual cells and lysosomes, which was most obvious following shorter periods of SSM development, when only sites with large amounts of iron are detected [50,71]. The differences probably reflect varying autophagic activity between cells and parts of the lysosomal compartment (see panel B in Figure 2). Following longer periods of development, a weak diffuse cytosolic staining became evident, more intense for J774 than for HeLa cells (compare panels A and B in Figure 2), indicating some cytosolic low mass iron. As a control for ironspecificity, some $\mathrm{J} 774$ cells were exposed for $4 \mathrm{~h}$ to $\mathrm{Fe}-\mathrm{Ft}$, which would result in intralysosomal ferritin degradation with release of low mass iron. Increased lysosomal iron was also obtained by feeding the cells a hydrated iron phosphate complex (formed by the addition of $\mathrm{FeCl}_{3}$ to complete culture medium at a final concentration of $30 \mu \mathrm{M}$ ) that will release free iron in the acidic lysosomal environment. Both of these compounds are taken up by endocytosis [50]. Such cells (panel A, micrographs b and c, respectively, in Figure 2) show an intense granular pattern producing a lysosome-type distribution. Since the endocytotic activity varies between cells [58], some cells showed heavy lysosomal iron-loading, while others did not. 


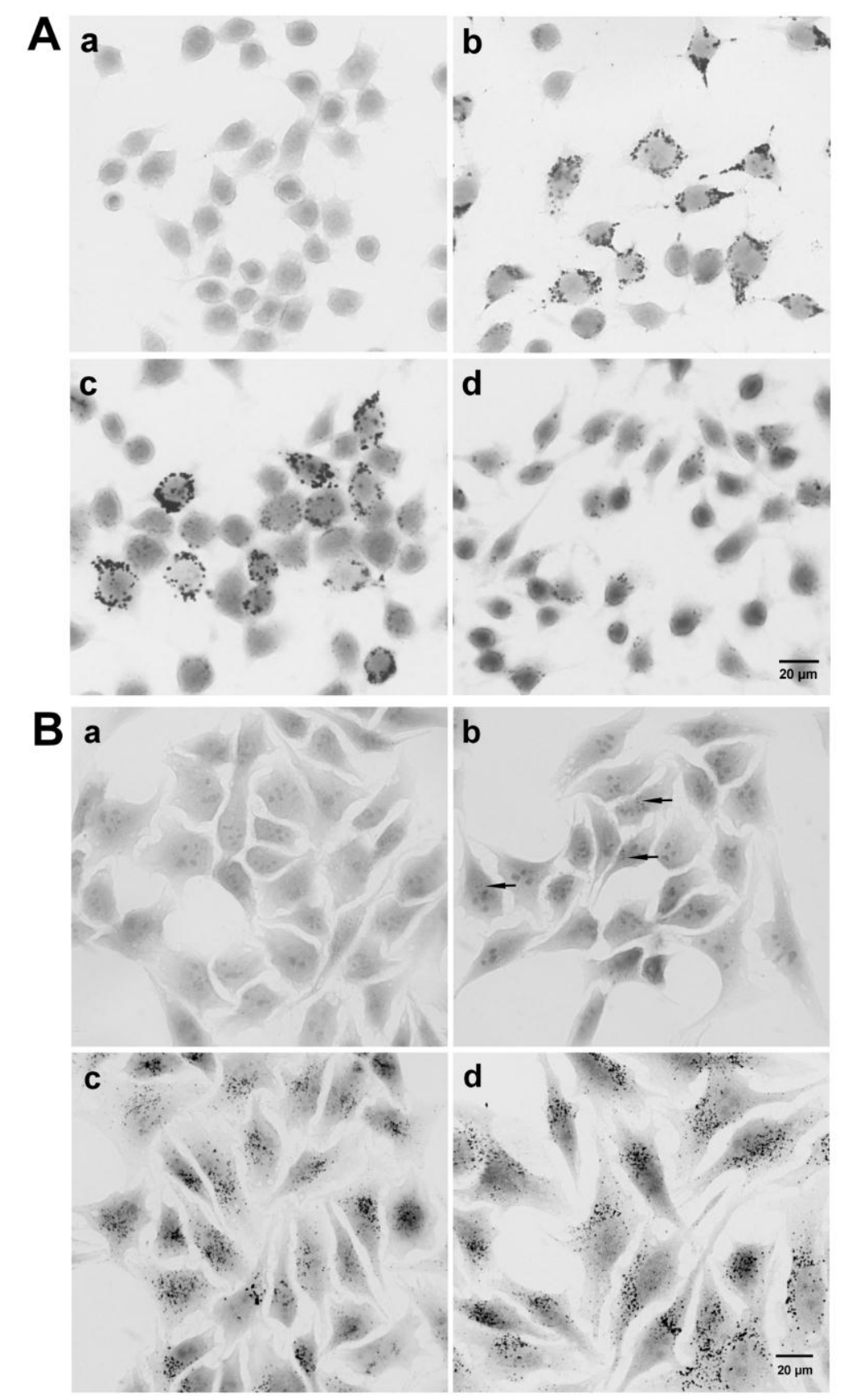

Figure 2. Panel A (micrographs a-d). J774 cells following cytochemical demonstration of low mass iron by the sulfide silver method (SSM). Micrographs a and d show control cells developed for 10 and 40 min, respectively. Only after the longer development, some positive dark granules appear (iron-containing lysosomes). Note the heterogeneity in iron content between and within cells. Micrograph $\mathbf{b}$ shows cells that were exposed to Fe-Ft $(0.1$ $\mu \mathrm{M}$ ) for $4 \mathrm{~h}$. A development time of $10 \mathrm{~min}$ is then enough to demonstrate heavily iron-loaded lysosomes. Note the occurence of a few unstained cells, which obviously did not endocytose. Micrograph c shows cells exposed for $4 \mathrm{~h}$ to the described hydrated iron-phosphate complex $(30 \mu \mathrm{M})$ and developed for $30 \mathrm{~min}$. Most cells contain iron loaded lysosomes, although some cells seem to have been inactive with respect to endocytosis.

Panel B (micrographs a-d). Cytochemical demonstration of low mass iron by the SSM in HeLa cells. HeLa cells were developed for $20 \mathrm{~min}$ (micrograph a), $25 \mathrm{~min}$ (micrograph b), $30 \mathrm{~min}$ (micrograph c) and $60 \mathrm{~min}$ (micrograph d). Note the gradual appearance of an increasing number of SSM-positive lysosomes indicating a large variation in their content of iron. That probably reflects whether or not individual lysosomes recently have been engaged in the degradation of any ferruginous material. Cells with iron-containing lysosomes are arrowed in micrograph $\mathbf{b}$.

The experiments were repeated three times. Images from one representative experiment are shown. 
Lysosomes are sensitive to oxidative stress due to their content of redox-active iron.

As a consequence of their redox-active iron content, lysosomes are damaged by oxidative stress. Figure $3 \mathrm{~A}$ demonstrates that already at the end of the oxidative stress period, the sensitive AO-relocation method picks up significant relocation of lysosomal AO to the cytosol, indicating LMP in a limited number of lysosomes. These more sensitive lysosomes are presumably particularly rich in redox-active iron following recent participation in the degradation of ferruginous materials. The relation between lysosomal iron and oxidative damage is demonstrated by the inhibitory effect on LMP by the lipophilic and lysosomotropic iron-chelator SIH (Figure 3A).

More pronounced LMP occurred later, as was shown with the AO-uptake method, which also demonstrates the presence of still intact lysosomes (Figure 3B). Apo-Ft obviously has the capacity to temporarily chelate intralysosomal iron following its endocytotic uptake, while, in contrast, Fe-Ft and the Fe-phosphate complex act as iron donors and increase the sensitivity of lysosomes to oxidative stress (Figure 3B).

By itself, enhanced endocytosis seems to give rise to a slight sensitization of lysosomes, as is seen for the cells in Fig. 3B that were exposed to apo-Ft, Fe-Ft or the iron-phosphate complex but not to hydrogen peroxide (empty bars). This finding (increase of 'pale cells' with reduced number of intact lysosomes from $\sim 5$ to $\sim 8 \%$ ) might be explained by the fact that professional scavenger cells (such as the macrophage-like J774 cells) produce an oxidative burst in relation to endocytosis, which may lead to a limited rupture of some particularly ironrich lysosomes. 


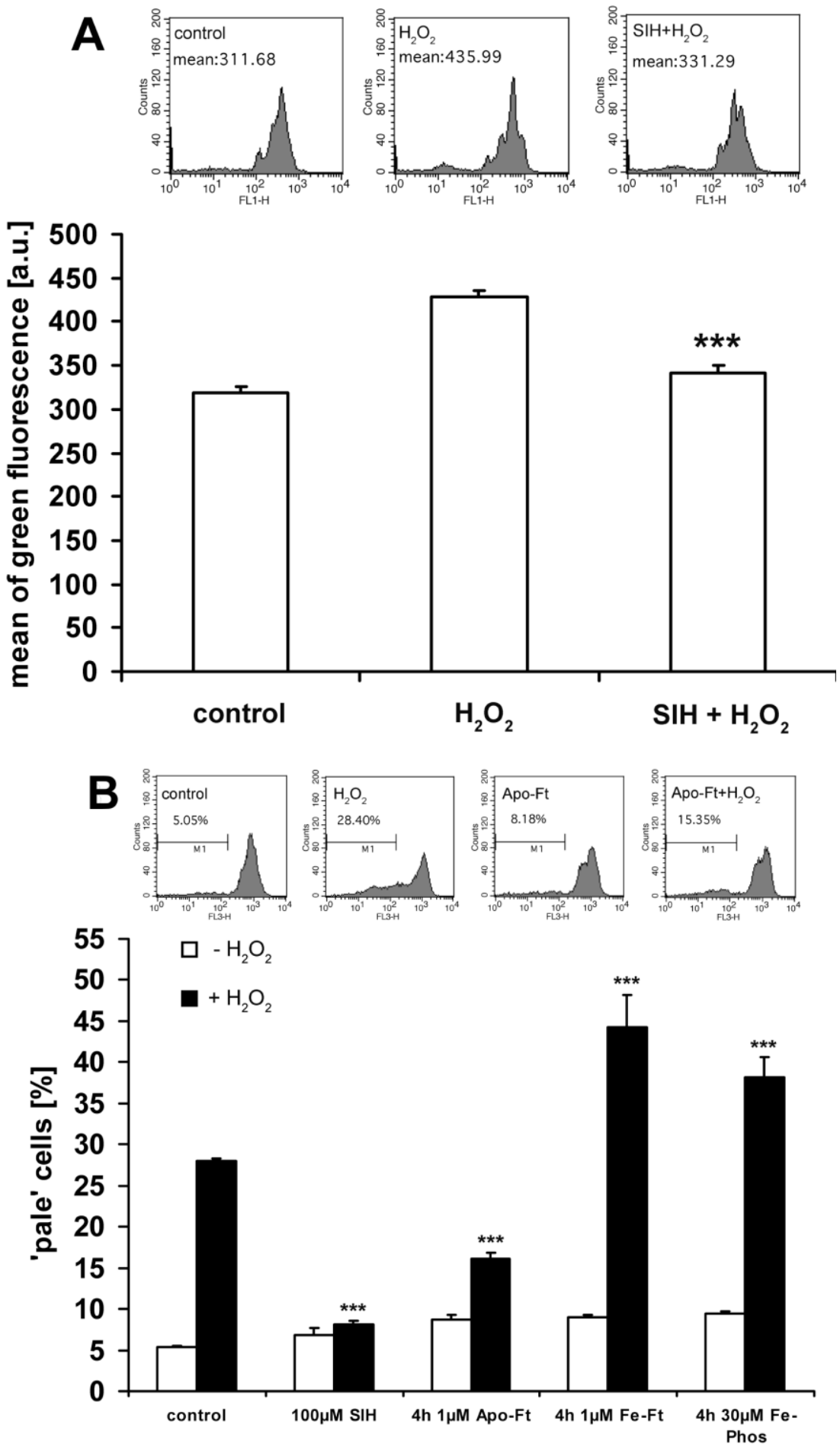

Figure 3. Panels A-B. Lysosomal destabilization is an early event following oxidative stress and is influenced by the lysosomal content of labile iron. The lysosomal stability of control J774 cells, and cells exposed to the hydrated iron-phosphate complex, to $\mathrm{Fe}-\mathrm{Ft}$ or to apo-Ft for $4 \mathrm{~h}$ was analysed by the two AO methods as described in the Materials and methods section. Results are presented as means \pm SD $(n=3-5)$.

A. To show that oxidative stress results in early lysosomal destabilization that is influenced by lysosomal labile iron, lysosomal stability was assayed with the sensitive AO-relocation method directly after end of the oxidative stress event. In some experiments, SIH was present together with hydrogen peroxide.

B. To confirm these results, using the less sensitive but more flexible AO-uptake technique, cells were exposed to the iron-compounds or to apo-Ft followed by oxidative stress as described. In some experiments, SIH was present together with the hydrogen peroxide. Cells were then returned to standard culture conditions and lysosomal stability was measured $6-8 \mathrm{~h}$ following end of the oxidative stress event. 
Depending on the magnitude of LMP apoptosis or necrosis follow.

Lysosomal rupture induces apoptosis or necrosis depending on the magnitude of lysosomal destabilization $[22,39,40,53-58]$. Using the Nicoletti method, it was found that a moderate oxidative stress induced an apoptotic-type DNA fragmentation, which was counteracted by exposure to SIH or apo-Ft (Figure 4). However, an initial exposure of cells to Fe-FT before the oxidative stress resulted in a dramatically increased cellular damage of mainly necrotic type, as judged by phase contrast microscopy, while the apoptotic response was depressed with a lower number of apoptotic nuclei (many necrotic nuclei undergo lysis and would not be detected by the Nicoletti method).

LMP and loss of mitochondrial membrane potential during oxidative stress start about simultaneously.

As reported earlier [63], chelation of lysosomal iron by SIH in relation to oxidative stress prevented both LMP and depression of mitochondrial membrane potential (results not shown). This finding suggests that hydrogen peroxide per se does not damage mitochondria. However, since SIH also would prevent mitochondrial low mass iron to react with hydrogen peroxide, the finding does not exclude mitochondrial iron-mediated damage. Since oxidative stress induces both $\Delta \Psi_{m}$ and early LMP after about the same delay (compare Figures $3 \mathrm{~A}$ and 5) it is not possible to tell with certainty if mitochondrial depolarization is secondary to lysosomal leak or if the two events initially develop independently.

Free lysosomal iron is rapidly transported to the cytosol, resulting in ferritin upregulation and ensuing lysosomal stabilization, presumably due to ferritin autophagy

Lysosomes of cells exposed for $4 \mathrm{~h}$ to $\mathrm{Fe}-\mathrm{Ft}$ were for some time thereafter substantially sensitized to oxidative stress (Figures $3 \mathrm{~B}$ and 4), indicating that the Fe-Ft is endocytosed and 
increases the lysosomal content of redox-active iron (see Figure 2, panel A, micrograph b). However, when such iron-loaded cells were subsequently kept at standard culture conditions (without any Fe-Ft in the medium) for another $2 \mathrm{~h}$, this enhanced lysosomal sensitivity became progressively reduced to the magnitude of that of control cells, suggesting that iron released in lysosomes is quickly transported to the cytoplasm (Figure 6).

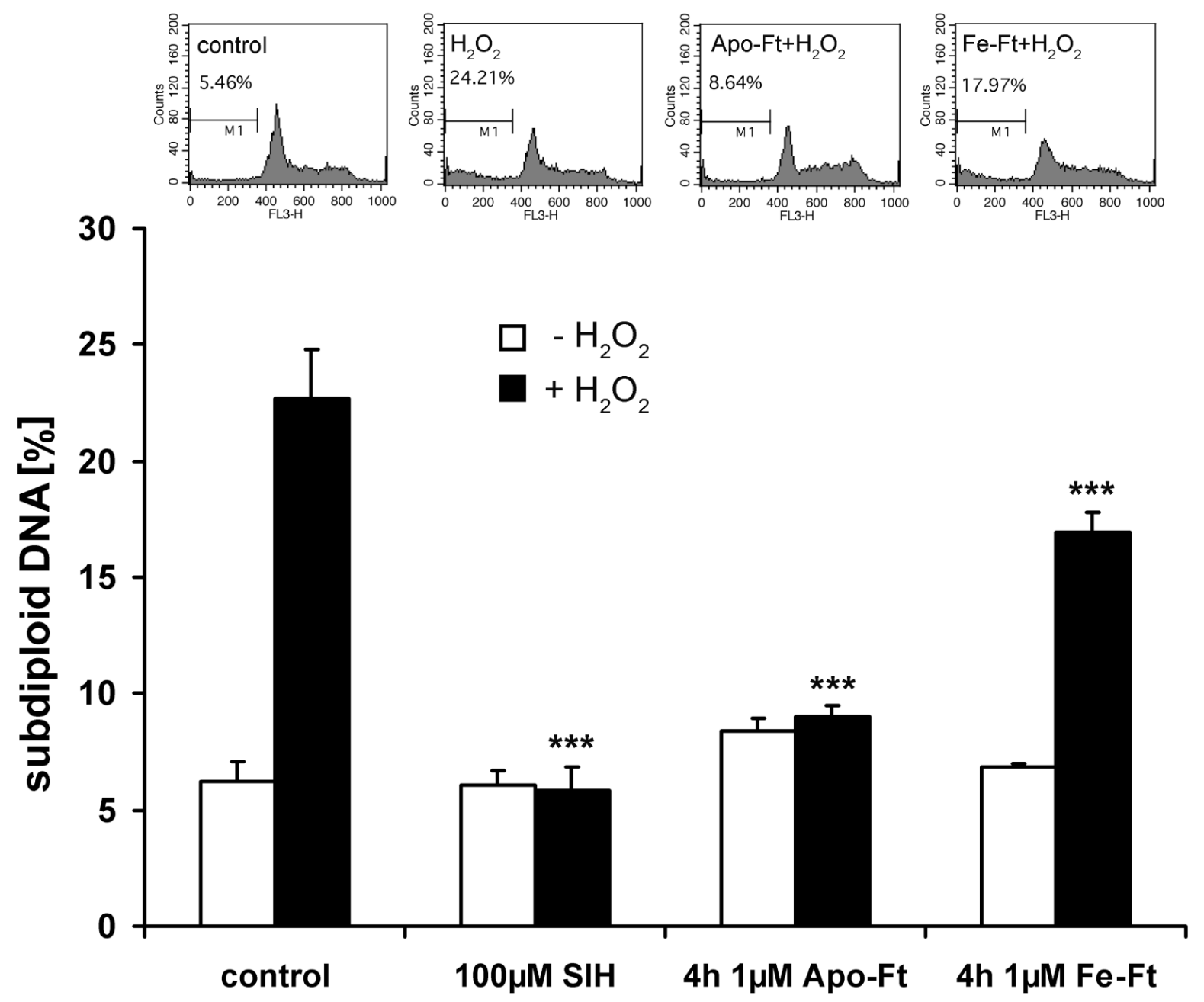

Figure 4. Influence of iron on oxidative stress-induced apoptosis/necrosis (Nicoletti technique). J774 cells were exposed to Fe-Ft, apo-Ft or SIH as described in the text and then to an oxidative stress event followed by culture at standard conditions for $7 \mathrm{~h}$. DNA fragmentation was assayed as described. Note that the exposure to Fe-Ft results in enhanced sensitivity and a reduced number of both haploid and diploid nuclei, indicating increased rate of necrosis over apoptosis. Results are given as means $\pm \mathrm{SD}(\mathrm{n}=3)$. 


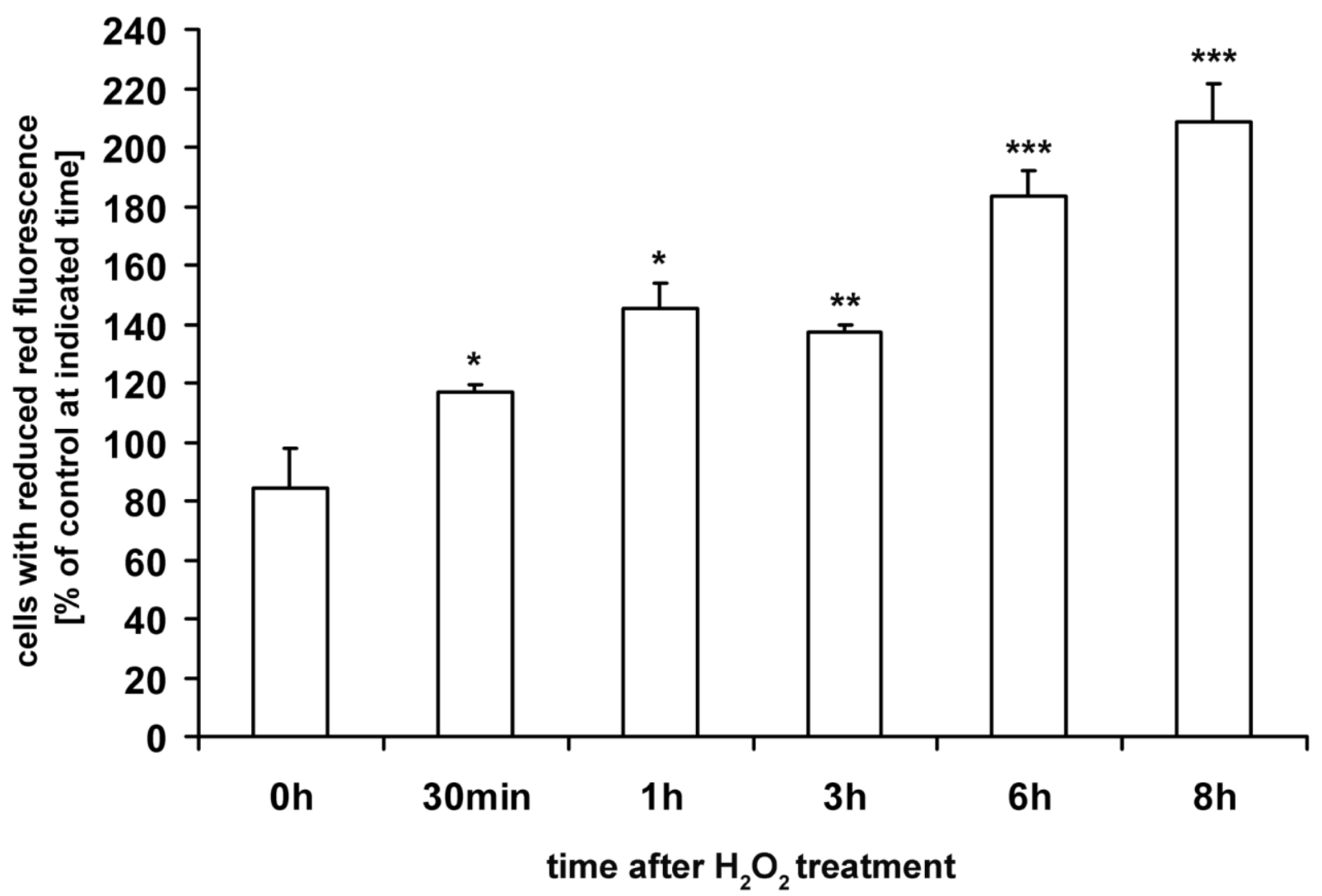

Figure 5. Change of mitochondrial membrane potential following oxidative stress. J774 cells were exposed for $30 \mathrm{~min}$ to $100 \mu \mathrm{M} \mathrm{H}_{2} \mathrm{O}_{2}$ in HBSS and then returned to standard culture conditions. At indicated time points, cells were exposed to $100 \mathrm{nM}$ TMRE for $15 \mathrm{~min}$ and red fluorescence was measured cytofluorometrically. Results are given as means \pm SD $(n=3)$.

Since Fe-Ft-induced lysosomal sensitization was completely reversed two hours following the end of the bolus exposure to Fe-Ft and, moreover, turned into a significant stabilization one and two hours later (Figure 6), we hypothesized that the release of iron from Fe-Ft inside the lysosomes, with subsequent transport to the cytosol, would result in upregulation of ferritin. We verified this by ferritin immunodetection (Figure 6, inset). This in turn should allow autophagy of enhanced amounts of non-iron-saturated ferritin with temporary binding of intralysosomal low mass iron in a non-redox-active state. 


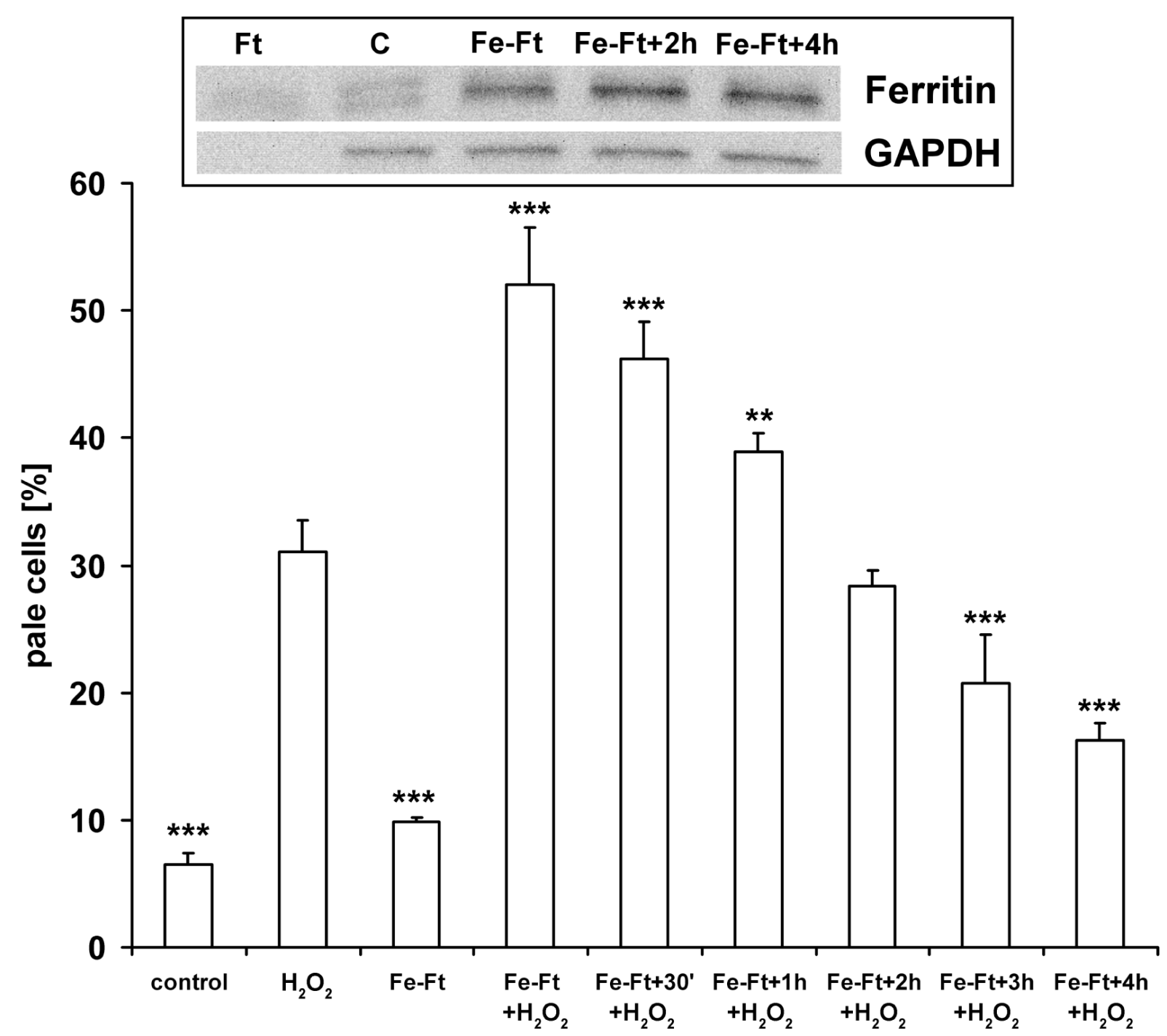

Figure 6. Lysosomal iron is rapidly relocated to the cytosol. $\mathrm{J} 774$ cells were pre-incubated for $4 \mathrm{~h}$ with Fe-Ft $(0.1 \mu \mathrm{M})$ under otherwise standard culture conditions. Cells were thereafter kept in fresh medium for indicated periods of time, before being exposed to a bolus dose of $100 \mu \mathrm{M} \mathrm{H}_{2} \mathrm{O}_{2}$ for $30 \mathrm{~min}$. Cells were then returned to standard culture conditions and lysosomal stability was measured (AO-uptake test) 6 - $8 \mathrm{~h}$ later. Note declining labilizing effect by time. After $2 \mathrm{~h}$ at standard culture conditions, the initially destabilizing effect of iron-overloading is converted to stabilization that is accentuated over time. This suggests relocation of iron to the cytosol as well as conversion of intralysosomal iron into a non-redoxactive form as a result of binding to autophagocytosed apo-Ft. Results are given as means \pm $\mathrm{SD}(\mathrm{n}=3-6)$.

Inset. Ferritin is upregulated following incubation of cells with Fe-FT. $50 \mu \mathrm{g}$ total cell lysate from $\mathrm{J} 774$ cells exposed to $1 \mu \mathrm{M}$ Fe-Ft $(\mathrm{Fe}-\mathrm{Ft})$ or not $(\mathrm{C})$ was size-separated in a polyacrylamide gel electrophoresis. For comparison $1 \mu \mathrm{g}$ horse spleen ferritin $(\mathrm{Ft})$ was run in parallel. Immunodetection of ferritin was done following protein transfer onto a nitrocellulose membrane. GAPDH immunodetection served as a control for equal loading of the lanes. Ferritin was quickly upregulated but since its autophagy is a slower process, lysosomal stabilization increased over time. 


\section{Cytosolic autophagy is enhanced following iron-starvation}

Autophagy is a proven and dominating mechanism for the release of iron from ferritin, although it is disputed whether it is the only one (reviewed in refs. $[8,10,29-43,72]$ ). To further analyze the possible change in autophagy mediated by iron-starvation, we exposed cells to the lipophilic ester calcein-AM, which, after passage through the plasma membrane, is cleaved by cytosolic esterases to form the fluorochromic, hydrophilic alcohol calcein, which is an iron-chelator that is widely used to assay cytosolic labile iron [70]. By following calceinexposed J774 cells by confocal microscopy, we found a rapid formation of calcein-containing lysosomes (confirmed by exposure to Lysotracker-red ${ }^{\circledR}$, result not shown). Within hours, the cytoplasm contained plenty of such lysosomes indicating pronounced cytosolic autophagy. Following an observation period of $15 \mathrm{~h}$, most calcein-containing cytoplasm was found inside the lysosomal compartment, leaving only a faint remaining calcein-induced fluorescence in the cytoplasm. This finding suggests a substantially enhanced autophagy of the cytosol and its ferritin due to iron-starvation (Figure 7, panel A). Cell division would not have resulted in a lysosomal pattern and a complete disappearance of cytosolic calcein fluorescence but only in a $50 \%$ reduction of cytosolic fluorescence. To verify that the weak cytosolic fluorescence at the end of the observation period was not a result of iron-mediated quenching of calcein fluorescence, additional SIH was added to some of the cultures. No increased fluorescence followed (results not shown).

When ferric iron chloride was added in pulses to buffered calcein $(\mathrm{pH} 7.4)$ significant, but not complete, depression of the fluorescence occurred (Figure 7, panel B). At pH 4.5, although initially low, fluorescence was not further depressed by addition of iron (results not shown). This shows that calcein does not bind iron at lysosomal $\mathrm{pH}$ and, consequently, only demonstrates cytosolic labile iron and not total cellular iron [70]. The reason for why autophagolysosomes show bright calcein-dependent fluorescence, in spite of their low $\mathrm{pH}$, 

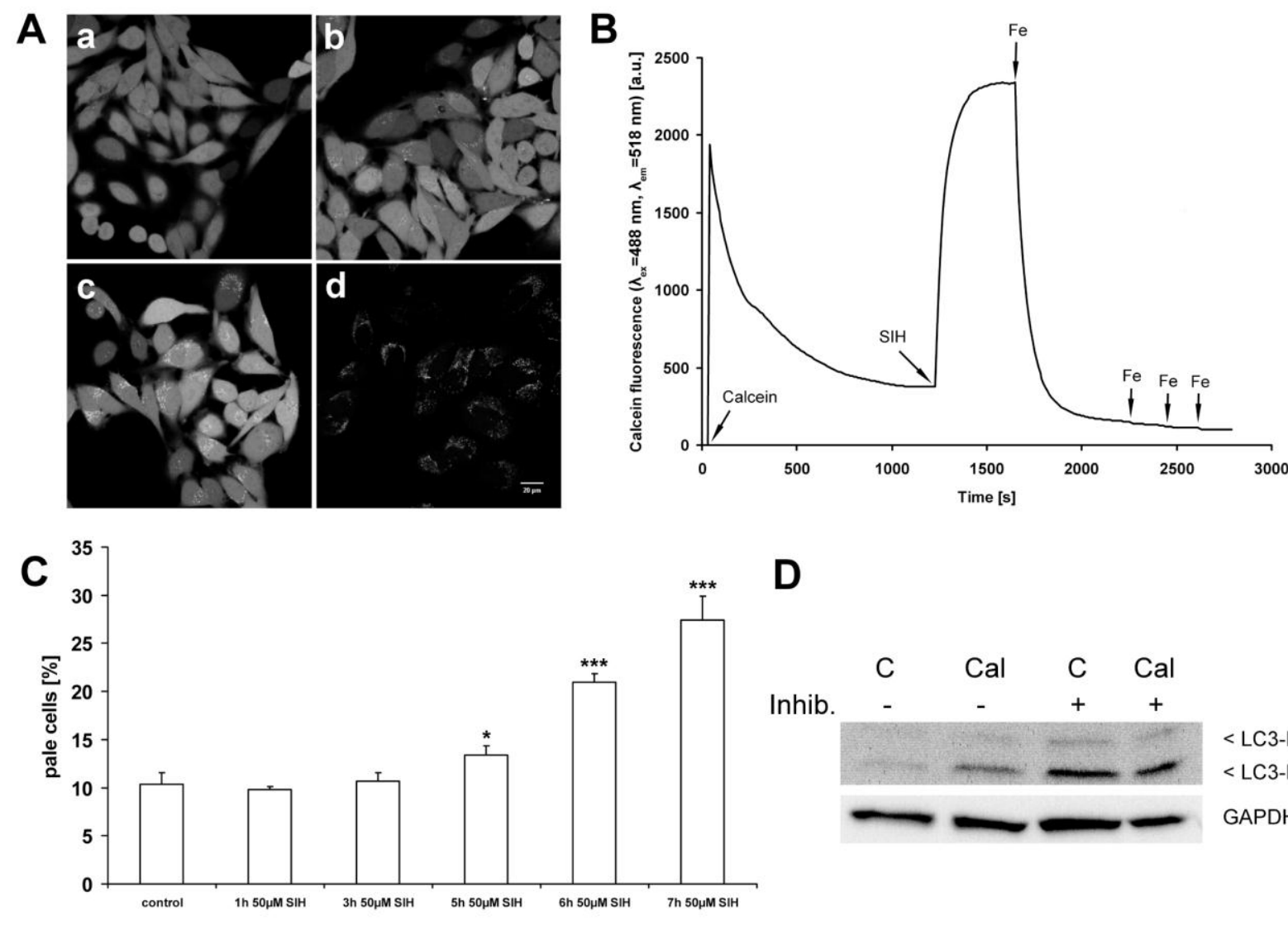

$<$ LC3-1

$<$ LC3-II GAPDH

Figure 7. Panel A. Assay of cytosolic autophagy using calcein and evaluation of iron-mediated quenching of calcein fluorescence. The cytosol of HeLa cells was loaded with calcein-AM, which after de-esterification forms the fluorochrome calcein. The latter does not permeate membranes and its fluorescence is quenched by labile iron (for details see the Materials and methods section). Over time more and more of the calcein-labelled cytosol accumulated in autophagosomes, indicating that calcein induced autophagy of the cytosol and its ferritin. Times after enrichment with calcein: micrograph $\mathrm{a}=$ 15 min, micrograph $b=2 \mathrm{~h}$, micrograph $\mathrm{c}=4 \mathrm{~h}$, micrograph $\mathrm{d}=15 \mathrm{~h}$. All confocal micrographs were taken with identical settings. Note the conversion of initial cytosolic fluorescence into fluorescence with a lysosomal pattern. As mentioned in the Results section, the addition to the $15 \mathrm{~h}$ cell cultures of SIH (final concentration $100 \mu \mathrm{M}$ ) did not enhance the calcein fluorescence. This shows that the almost complete absence of cytosolic calcein-mediated fluorescence at $15 \mathrm{~h}$ is not an effect of iron-quenching but rather a result of cytosolic autophagy (also see panel B).

The experiment was repeated three times and cells from one representative experiment are shown.

Panel B. Calcein was added to $150 \mathrm{mM}$ HEPES buffer ( $\mathrm{pH}$ 7.4) to a final concentration of $50 \mathrm{nM}$. To de-quench the calcein fluorescence that slowly takes place, being a function of iron contamination of the buffer, SIH was added to a final concentration of $5 \mu \mathrm{M}$. Then the final concentration of iron was increased in $5 \mu \mathrm{M}$ steps as indicated. Even after repeated additions of iron, the calcein fluorescencence was not completely quenched.

Panel C. Induction of iron-starvation by exposure to the lipophilic iron chelator SIH. J774 cells were exposed to $50 \mu \mathrm{M}$ SIH for indicated periods of time and lysosomal stability was then assayed with the AO uptake method. LMP is an early upstream event in apoptosis induced by iron-starvation. Results are given as means $\pm \mathrm{SD}(\mathrm{n}=4)$.

Panel D. Autophagosome formation following calcein treatment. HeLa cells were exposed for 15 min to calcein-AM (Cal) or not (C) and then transferred to standard conditions for $15 \mathrm{~h}$. Some cells were initially treated for $4 \mathrm{~h}$ with protease inhibitors (Inhib.). Immunodetection of LC3 was done with 50 $\mu \mathrm{g}$ total cell lysate. GAPDH served as a loading control. 
reflects a high calcein concentration within the lysosomes (calcein is an alcohol that cannot penetrate membranes and, therefore, becomes concentrated when the autophagolysosomes shrink due to degradation of their content and export to the cytosol of water and degradation products) [70]. The inability of calcein to bind iron at low $\mathrm{pH}$, leaving lysosomal iron free to relocate to the cytosol, is also supported by the finding that calcein-exposed cells did not die even after prolonged exposure, while SIH-exposed cells went into apoptosis after $\sim 6 \mathrm{~h}$.

\section{Iron-starvation induces lysosomal labilization followed by apoptosis}

It is well known that iron-starvation induces apoptosis, probably with a velocity that is related to the cellular requirement for iron. Following exposure to the iron chelator SIH (20$50 \mu \mathrm{M}$ ), we found that some $\mathrm{J} 774$ cells started to show early morphological signs of apoptosis already after about $6 \mathrm{~h}$, while the HeLa cells withstood iron starvation for up to $24 \mathrm{~h}$ before significant apoptosis took place (results not shown). In order to find out if LMP was involved in this form of apoptosis, we analysed lysosomal stability, using the AO-uptake method, following exposure of J774 cells to SIH. We found that LMP was induced by SIH and coincided with the initiation of apoptosis (Figure 7, panel C). SIH, by binding lysosomal iron, has been found to prevent short-term oxidative stress-induced apoptosis [63], while prolonged SIH-mediated iron starvation leads to lysosomal rupture and apoptosis by a mechanism that must be different from that of oxidative stress.

HeLa cells show enhanced autophagy following iron-starvation, suggesting increased lysosomal turnover of ferritin.

As shown in Figure 7, panel D, the LC3-I and LC3-II protein bands are only weakly detected in control HeLa cells. Calcein-induced iron starvation leads to accumulation of the glycated LC3-II protein, indicating formation of autophagosomes. The notion that the 
increased LC3-flux is due to enhanced autophagy is supported by the finding that the LC3-II band is also increased if the cells are treated with lysosomal protease inhibitors prior to iron starvation (in order to prevent LC3 degradation). The finding suggests that iron-starvation induces ferritin autophagy in an effort to increase the availability of iron for anabolic purposes. 


\section{DISCUSSION}

Although the importance of redox-active iron for the formation of hydroxyl radicals and, thereby, for the cytotoxicity of oxidative stress has been repeatedly pointed out in recent years, the connection is still far from generally recognized. For example: many 'anti-oxidants' are considered 'radical scavengers' when in reality they are iron-binding compounds that, rather than binding radicals, preclude their formation by preventing Fenton-type reactions. Good examples of such compounds are various polyphenols, e.g., those that naturally occur in red wine, olive oil, and a variety of fruits and berries (for reviews see refs. [22,72-74]). Until now, our knowledge on how cells handle the substantial amount of low mass (i.e. unchelated) iron that is constantly released within their lysosomal compartments due to the autophagic degradation of ferruginous materials, which sensitizes lysosomes to oxidative stress, has been rudimentary. Additional understanding of this process may help to clarify the mechanisms behind a variety of diseases related to oxidative stress, as well as the consequences of the iron-overloading, that seems to be related to normal ageing and a number of common neurodegenerative disorders, such as age-related macular degeneration (AMD), Parkinson's, and Alzheimer's diseases. Tentatively, lysosomal iron-overload may result in LMP and related cell death in those conditions $[25,72,75,76]$.

In the present study, we found that iron-starvation, mediated by exposing J774 and HeLa cells in culture, to either the strong lipophilic iron-chelator salicylaldehyde isonicotinoyl hydrazone $(\mathrm{SIH})$ or a less potent hydrophilic iron chelator, calcein, induced substantial autophagy within a few hours. This increased autophagy allows degradation of ferritin and the release of iron, which was demonstrated by a shift of the LC3-I protein to its LC3-II form, indicating attachment of the LC3-II protein to the phagophores, which is an early step in autophagy [77]. These results concur with the findings of recent studies $[10,29,30,42]$ and suggest that iron is liberated by ferritin autophagy and ensuing degradation. Some of the old 
arguments for the hypothesis of direct cytoplasmic release of iron are less than convincing. For example: since lysosomes contain a spectrum of proteases, the failure to prevent ironrelease by exposing cells to a single protease inhibitor (e.g. pepstatin A) does not prove much. Neither does the statement that increasing the lysosomal $\mathrm{pH}$, using lysosomotropic agents such as chloroquine or ammonia, would prevent degradation. Indeed, some lysosomal cathepsins have a narrow $\mathrm{pH}$ optimum, but others are able to work quite efficiently also when the $\mathrm{pH}$ is close to 7 , albeit with diminished half-lives [78]. Moreover, some common inhibitors used to evaluate the possible role of proteasomes in ferritin degradation, for example MG132, also inhibit lysosomal proteases [79]. Finally and compellingly, for decades electron microscopists have described the presence of ferritin molecules inside the lysosomal compartment (for a review see ref. [7]).

Since redox-active $\mathrm{Fe}(\mathrm{II})$ iron catalyzes a homolytic cleavage of hydrogen peroxide to form the highly reactive and strongly oxidizing hydroxyl radical $\left(\mathrm{HO}^{\circ}\right)$, lysosomes are at risk under cellular oxidative stress. Resulting lysosomal LMP, with release of enclosed iron and potent hydrolytic enzymes to the cytosol, may induce apoptosis/necrosis [80]. Obviously, rapid export of lysosomal low mass iron to the cytosol for incorporation into ferritin, or its lysosomal presence in a non-redox-active form would be beneficial for the survival of cells during episodes of oxidative stress. To this end, autophagy of iron-binding molecules, such as metallothioneins and heat shock proteins would be protective by temporarily binding lysosomal low-mass iron [41,81-83]. The effect of autophagocytosed ferritin on lysosomal stability may depend upon the ferritin's iron-load. If sufficient additional iron-binding capacity is present, lysosomal redox-active iron will be depressed and LMP prevented. However, if most ferritin is heavily iron-loaded no further uptake will take place and its eventual degradation will further enhance lysosomal redox-active iron and sensitize the lysosomal compartment to oxidative stress. 
Although there is a basal, constant level of autophagy, this process can be up- or downregulated and also made specific (for a review see ref. [72]). As a result, there is a relation between the presence in the cytosol and lysosomes of macromolecules that are turned over by autophagy. Not surprisingly, therefore, it has been found that cells that are rich in ferritin, metallothioneins and heat shock proteins, which are all capable of iron-binding (for a review see ref. [72]), are also resistant to oxidative stress. Numerous studies have demonstrated that such phase II (stress) proteins provide major protection against oxidative injury. Especially in the case of ferritin, the sensitivity of cells to such stress is inversely correlated with its cellular concentration [6,84-86]. Ferritin is not only an iron-storage protein but also a custodian against the generation of Fenton-type reactions in the cytosol. However, the most dangerous location for the production of reactive oxygen-derived radicals would appear to be in the lysosomes. Following lysosomal rupture, a multitude of powerful lytic enzymes and redoxactive iron is released to the cytosol. Autophagy of ferritin and other iron-binding proteins would diminish this risk by temporarily chelating labile iron within the lysosome. Consequently, it seems logical that oxidative stress upregulates phase II (stress) proteins [87], at least some of which (e.g., ferritin, metallothioneins and heat shock protein 70) may temporarily chelate iron following autophagy. Ferritin synthesis is complex and involves transcriptional regulation via antioxidative response elements (ARE) as well as regulation on the mRNA level via iron response elements (IRE) [5].

Clearly, both lysosomal and cytosolic iron is in transit, although little is known about the half-lives of either of these fractions. However, considering the carefulness by which nature handles labile iron, it may be assumed that it does not remain in the lysosomes, nor in the cytosol, longer than necessary. The findings presented here confirm this assumption. We found that when a pulse dose of $\mathrm{Fe}-\mathrm{Ft}$ is administered to endocytically active, macrophagelike J774 cells, redox-active low mass iron is released within their lysosomal compartment, 
where it sensitizes lysosomes, and thereby the whole cell, to oxidative stress, although only for a short period of time. Two hours after the end of Fe-Ft exposure, cells were no more sensitive than controls. Moreover, and quite interestingly, the sensitivity then further declined for another few hours.

Cytosolic ferritin is normally never completely iron-saturated, implying that following autophagy, and before its degradation, it may be able to bind lysosomal low mass iron and for some period of time keep it in a non-redox-active form [41]. If we assume that a cell's cytoplasm is rich in non-Fe-saturated ferritin and/or other possible iron-chelating molecules, e.g. metallothioneins and heat shock proteins that are rich in thiol $(-\mathrm{SH})$ groups $[81,82]$, an autophagic influx to the lysosomal compartment of such structures would create a steady state balance between redox-active and bound intralysosomal iron, where the latter form of iron would be favored. Only in cases of severe iron overloading, such as in primary or secondary hemochromatosis, we would expect that cytosolic ferritin becomes iron-saturated, or nearly so. Under such conditions, we would expect that autophagy of Fe-saturated ferritin increases redox-active low mass iron in the lysosomes and sensitizes the cell to oxidative stress. Our finding that degradation of endocytosed heavily Fe-saturated ferritin probably also with some adsorbed iron (Fe-Ft) increased lysosomal sensitivity to oxidative stress shows that such a scenario may, indeed, take place. The commercial (Sigma) solution of "Fe-saturated ferritin" that was used probably contains not yet incorporated adventitious iron, and some free iron as well, that may exaggerate lysosomal iron-loading. Nevertheless, it seems reasonable to assume that in iron-overload conditions, autophagy of ferritin would bring in substantial amounts of iron to lysosomes. Interestingly, an iron-dependent toxic effect of endocytosed ferritin was recently described by Bresgen et al. [88].

In addition to the export of lysosomal labile iron to the cytoplasm by DMT1/Nramp2 [11,12] or TRPML1/MCOLN1 [13], autophagy of iron-binding proteins, such as non-iron- 
saturated ferritin, would be an effective way of keeping lysosomal redox-active iron below a level that would jeopardize the stability of lysosomes at moderately elevated concentrations of hydrogen peroxide. Occasionally, periods of oxidative stress will occur and give rise to influx of hydrogen peroxide to the lysosomal compartment. Since lysosomes lack peroxidedegrading enzymes, even small amounts of hydrogen peroxide may induce substantial damage if $\mathrm{Fe}(\mathrm{II})$ is available, the suppression of such redox-active iron by binding to ferritin and other iron-binding proteins may be vitally important to cell survival.

Interestingly, the lysosomal sensitization that followed exposure of cells to Fe-Ft before oxidative stress lasted only for a short time and was then replaced by its opposite, namely stabilization. This suggests that the transport to the cytosol of iron that is set free inside lysosomes is a rapid process, and that the relocated iron upregulates apo-ferritin, which, following autophagy, helps to stabilize lysosomes against oxidative stress.

The interesting finding that iron-starvation, accomplished by exposing cells to the lipophilic iron chelator SIH, causes lysosomal labilization followed by apoptosis, requires some comments. This discovery suggests that the release of lysosomal contents is an early step in apoptosis, not only, as is well known, following oxidative stress or rupture induced by lysosomotropic detergents, but also secondary to other apoptogenic stimuli. It should be noted that in the presence of SIH, lysosomal rupture does not occur due to oxidative stress because lysosomal iron is then bound in a non-redox-active form [63]. Thus another reason needs to be found, perhaps one in line with the observation that p53-activation rapidly results in lysosomal rupture [66], and with the finding that a member (LAPF) of a newly discovered family of proteins localizes to lysosomes and induces LMP and ensuing apoptosis by anchoring the p53 protein to the lysosomal membrane $[89,90]$. Together these new results support the hypothesis that lysosomal destabilization and a lysosomal-mitochondrial cross 
talk [75] may be a much more general phenomenon in the initiation of apoptosis than previously considered.

In conclusion, since ferritin stores iron in a non-redox-active form, it is acting as a potent anti-oxidant and a safeguard against hazardous iron-catalyzed oxidative reactions. It has been shown previously that downregulation of $\mathrm{H}$-ferritin by siRNA or overexpression of a mutated $\mathrm{H}$-ferritin chain results in an increase of the labile iron pool and sensitization of cells to oxidative stress [91-93]. The same was found following overexpression of mutated L-ferritin variants [94]. For a review see ref. [95]. Furthermore, deletion of the H-ferritin gene by homologous recombination in mice was found to be lethal early during embryonic development [96], while L-ferritin mutations are associated with neuroferritinopathies [94].

Ferritin seems to play its role as an antioxidant not only in the cytosol, but also inside lysosomes following its autophagy [41,81]. When non-Fe-saturated ferritin is autophagocytosed, it seems to be capable of temporarily reducing the level of redox-active iron, while autophagy of Fe-saturated ferritin will have the opposite effect. An important route of iron-release from ferritin seems to involve its autophagy and ensuing degradation [42], even if this is not the only way of iron-release from ferritin. There are thus reasons to consider ferritin an important regulator of lysosomal and cellular stability under conditions of oxidative stress. The transport of released low mass iron from the lysosomal compartment to the cytosol seems to be rapid, stressing the connection between LMP and iron-catalyzed oxidative processes. Interestingly, it was found that apoptosis induced by iron-starvation was preceded by LMP, suggesting it to be a more common upstream process in apoptosis than so far considered. 


\section{ACKNOWLEDGMENTS}

Supported by the Linköping University Hospital Research Fund (ALF and FoU) and the Lions Research Foundation

\section{LIST OF ABBREVIATIONS}

Apo-Ft, apo-ferritin; AO, acridine orange base; Fe-Ft, heavily iron-loaded ferritin, probably with some adsorbed iron; HBSS, Hank's balanced salt solution with glucose; LMP, lysosomal membrane permeabilization; PI, propidium iodide; SIH, salicylaldehyde isonicotinoyl hydrazone; SSM, sulfide-silver method; TMRE, tetramethylrhodamine ethyl ester. 


\section{REFERENCES}

[1] Gutteridge, J. M. The role of superoxide and hydroxyl radicals in phospholipid peroxidation catalysed by iron salts. FEBS Lett. 150:454-458; 1982.

[2] Halliwell, B.; Gutteridge, J. M. C. The chemistry of free radicals and related 'reactive species'. In: Halliwell, B.; Gutteridge, J. M. C., eds. Free Radicals in Biology and Medicine. Oxford: Oxford University Press; 2003: 36-104.

[3] Eaton, J. W.; Qian, M. Molecular bases of cellular iron toxicity. Free Radic. Biol. Med. 32:833-840; 2002.

[4] Harrison, P. M.; Arosio, P. The ferritins: molecular properties, iron storage function and cellular regulation. Biochim. Biophys. Acta 1275:161-203; 1996.

[5] Hintze, K. J.; Theil, E. C. Cellular regulation and molecular interactions of the ferritins. Cell. Mol. Life Sci. 63:591-600; 2006.

[6] Torti, F. M.; Torti, S. V. Regulation of ferritin genes and protein. Blood 99:3505$3516 ; 2002$.

[7] Koorts, A. M.; Viljoen, M. Ferritin and ferritin isoforms I: Structure-function relationships, synthesis, degradation and secretion. Arch. Physiol. Biochem. 113:30-54; 2007. [8] Kidane, T. Z.; Sauble, E.; Linder, M. C. Release of iron from ferritin requires lysosomal activity. Am. J. Physiol. Cell Physiol. 291:C445-455; 2006.

[9] Munro, H. N.; Linder, M. C. Ferritin: structure, biosynthesis, and role in iron metabolism. Physiol. Rev. 58:317-396; 1978.

[10] De Domenico, I.; Vaughn, M. B.; Li, L.; Bagley, D.; Musci, G.; Ward, D. M.; Kaplan, J. Ferroportin-mediated mobilization of ferritin iron precedes ferritin degradation by the proteasome. EMBO J. 25:5396-5404; 2006.

[11] Forbes, J. R.; Gros, P. Iron, manganese, and cobalt transport by Nramp1 (Slc11a1) and Nramp2 (Slc11a2) expressed at the plasma membrane. Blood 102:1884-1892; 2003. 
[12] Hubert, N.; Hentze, M. W. Previously uncharacterized isoforms of divalent metal transporter (DMT)-1: implications for regulation and cellular function. Proc. Natl. Acad. Sci. U. S. A. 99:12345-12350; 2002.

[13] Dong, X. P.; Cheng, X.; Mills, E.; Delling, M.; Wang, F.; Kurz, T.; Xu, H. The type IV mucolipidosis-associated protein TRPML1 is an endolysosomal iron release channel. Nature 455:992-996; 2008.

[14] Hentze, M. W.; Muckenthaler, M. U.; Andrews, N. C. Balancing acts: molecular control of mammalian iron metabolism. Cell 117:285-297; 2004.

[15] Dunn, L. L.; Rahmanto, Y. S.; Richardson, D. R. Iron uptake and metabolism in the new millennium. Trends Cell Biol. 17:93-100; 2007.

[16] Kalinowski, D. S.; Richardson, D. R. The evolution of iron chelators for the treatment of iron overload disease and cancer. Pharmacol. Rev. 57:547-583; 2005.

[17] Richardson, D. R.; Ponka, P. The molecular mechanisms of the metabolism and transport of iron in normal and neoplastic cells. Biochim. Biophys. Acta 1331:1-40; 1997.

[18] Li, J. Y.; Paragas, N.; Ned, R. M.; Qiu, A.; Viltard, M.; Leete, T.; Drexler, I. R.; Chen, X.; Sanna-Cherchi, S.; Mohammed, F.; Williams, D.; Lin, C. S.; Schmidt-Ott, K. M.; Andrews, N. C.; Barasch, J. Scara5 is a ferritin receptor mediating non-transferrin iron delivery. Dev. Cell 16:35-46; 2009.

[19] Li, L.; Fang, C. J.; Ryan, J. C.; Niemi, E. C.; Lebron, J. A.; Bjorkman, P. J.; Arase, H.; Torti, F. M.; Torti, S. V.; Nakamura, M. C.; Seaman, W. E. Binding and uptake of H-ferritin are mediated by human transferrin receptor-1. Proc. Natl. Acad. Sci. U. S. A. 107:3505-3510; 2010.

[20] Brun, A.; Brunk, U. Histochemical indications for lysosomal localization of heavy metals in normal rat brain and liver. J. Histochem. Cytochem. 18:820-827; 1970. 
[21] Terman, A.; Brunk, U. T. Oxidative stress, accumulation of biological 'garbage', and aging. Antioxid. Redox Signal. 8:197-204; 2006.

[22] Kurz, T.; Terman, A.; Brunk, U. T. Autophagy, ageing and apoptosis: the role of oxidative stress and lysosomal iron. Arch. Biochem. Biophys. 462:220-230; 2007.

[23] Killilea, D. W.; Wong, S. L.; Cahaya, H. S.; Atamna, H.; Ames, B. N. Iron accumulation during cellular senescence. Ann. N. Y. Acad. Sci. 1019:365-367; 2004.

[24] Polla, A. S.; Polla, L. L.; Polla, B. S. Iron as the malignant spirit in successful ageing. Ageing Res. Rev. 2:25-37; 2003.

[25] Berg, D.; Youdim, M. B. Role of iron in neurodegenerative disorders. Top. Magn. Reson. Imaging 17:5-17; 2006.

[26] Dunaief, J. L. Iron induced oxidative damage as a potential factor in age-related macular degeneration: the Cogan Lecture. Invest. Ophthalmol. Vis. Sci. 47:4660-4664; 2006.

[27] Dröge, W.; Schipper, H. M. Oxidative stress and aberrant signaling in aging and cognitive decline. Aging Cell 6:361-370; 2007.

[28] Kell, D. B. Iron behaving badly: inappropriate iron chelation as a major contributor to the aetiology of vascular and other progressive inflammatory and degenerative diseases. $B M C$ Med. Genomics 2:2; 2009.

[29] Takagi, H.; Shi, D.; Ha, Y.; Allewell, N. M.; Theil, E. C. Localized unfolding at the junction of three ferritin subunits. A mechanism for iron release? J. Biol. Chem. 273:18685$18688 ; 1998$.

[30] Liu, X.; Jin, W.; Theil, E. C. Opening protein pores with chaotropes enhances Fe reduction and chelation of Fe from the ferritin biomineral. Proc. Natl. Acad. Sci. U. S. A. 100:3653-3658; 2003.

[31] Bridges, K. R.; Hoffman, K. E. The effects of ascorbic acid on the intracellular metabolism of iron and ferritin. J. Biol. Chem. 261:14273-14277; 1986. 
[32] Roberts, S.; Bomford, A. Ferritin iron kinetics and protein turnover in K562 cells. $J$. Biol. Chem. 263:19181-19187; 1988.

[33] Sakaida, I.; Kyle, M. E.; Farber, J. L. Autophagic degradation of protein generates a pool of ferric iron required for the killing of cultured hepatocytes by an oxidative stress. Mol. Pharmacol. 37:435-442; 1990.

[34] Vaisman, B.; Fibach, E.; Konijn, A. M. Utilization of intracellular ferritin iron for hemoglobin synthesis in developing human erythroid precursors. Blood 90:831-838; 1997.

[35] Radisky, D. C.; Kaplan, J. Iron in cytosolic ferritin can be recycled through lysosomal degradation in human fibroblasts. Biochem. J. 336:201-205; 1998.

[36] Konijn, A. M.; Glickstein, H.; Vaisman, B.; Meyron-Holtz, E. G.; Slotki, I. N.; Cabantchik, Z. I. The cellular labile iron pool and intracellular ferritin in K562 cells. Blood 94:2128-2134; 1999.

[37] Kwok, J. C.; Richardson, D. R. Examination of the mechanism(s) involved in doxorubicin-mediated iron accumulation in ferritin: studies using metabolic inhibitors, protein synthesis inhibitors, and lysosomotropic agents. Mol. Pharmacol. 65:181-195; 2004.

[38] Tenopoulou, M.; Doulias, P. T.; Barbouti, A.; Brunk, U.; Galaris, D. Role of compartmentalized redox-active iron in hydrogen peroxide-induced DNA damage and apoptosis. Biochem. J. 387:703-710; 2005.

[39] Yu, Z.; Persson, H. L.; Eaton, J. W.; Brunk, U. T. Intralysosomal iron: a major determinant of oxidant-induced cell death. Free Radic. Biol. Med. 34:1243-1252; 2003.

[40] Persson, H. L.; Yu, Z.; Tirosh, O.; Eaton, J. W.; Brunk, U. T. Prevention of oxidantinduced cell death by lysosomotropic iron chelators. Free Radic. Biol. Med. 34:1295-1305; 2003.

[41] Garner, B.; Roberg, K.; Brunk, U. T. Endogenous ferritin protects cells with ironladen lysosomes against oxidative stress. Free Radic. Res. 29:103-114; 1998. 
[42] Zhang, Y.; Mikhael, M.; Xu, D.; Li, Y.; Soe-Lin, S.; Ning, B.; Li, W.; Nie, G.; Zhao, Y.; Ponka, P. Lysosomal proteolysis is the primary degradation pathway for cytosolic ferritin and cytosolic ferritin degradation is necessary for iron exit. Antioxid. Redox. Signal. 13:999$1009 ; 2010$.

[43] De Domenico, I.; Ward, D. M.; Kaplan, J. Specific iron chelators determine the route of ferritin degradation. Blood 114:4546-4551; 2009.

[44] Shintani, T.; Klionsky, D. J. Autophagy in health and disease: a double-edged sword. Science 306:990-995; 2004.

[45] Yorimitsu, T.; Klionsky, D. J. Autophagy: molecular machinery for self-eating. Cell Death Differ. 12 Suppl 2:1542-1552; 2005.

[46] Suzuki, K.; Ohsumi, Y. Molecular machinery of autophagosome formation in yeast, Saccharomyces cerevisiae. FEBS Lett. 581:2156-2161; 2007.

[47] Levine, B.; Klionsky, D. J. Development by self-digestion: molecular mechanisms and biological functions of autophagy. Dev. Cell 6:463-477; 2004.

[48] Cuervo, A. M.; Bergamini, E.; Brunk, U. T.; Dröge, W.; Ffrench, M.; Terman, A. Autophagy and aging: The importance of maintaining "clean" cells. Autophagy 1:131-140; 2005.

[49] Terman, A.; Brunk, U. T. The aging myocardium: roles of mitochondrial damage and lysosomal degradation. Heart Lung Circ. 14:107-114; 2005.

[50] Zdolsek, J. M.; Roberg, K.; Brunk, U. T. Visualization of iron in cultured macrophages: a cytochemical light and electron microscopic study using autometallography. Free Radic. Biol. Med. 15:1-11; 1993.

[51] Terman, A.; Brunk, U. T. Lipofuscin: mechanisms of formation and increase with age. APMIS 106:265-276; 1998. 
[52] Brunk, U. T.; Terman, A. Lipofuscin: mechanisms of age-related accumulation and influence on cell function. Free Radic. Biol. Med. 33:611-619; 2002.

[53] Kurz, T.; Leake, A.; Von Zglinicki, T.; Brunk, U. T. Relocalized redox-active lysosomal iron is an important mediator of oxidative-stress-induced DNA damage. Biochem. J. 378:1039-1045; 2004.

[54] Terman, A.; Kurz, T.; Gustafsson, B.; Brunk, U. T. Lysosomal labilization. IUBMB Life 58:531-539; 2006.

[55] Zhao, M.; Antunes, F.; Eaton, J. W.; Brunk, U. T. Lysosomal enzymes promote mitochondrial oxidant production, cytochrome c release and apoptosis. Eur. J. Biochem. 270:3778-3786; 2003.

[56] Brunk, U. T.; Svensson, I. Oxidative stress, growth factor starvation and Fas activation may all cause apoptosis through lysosomal leak. Redox Rep 4:3-11; 1999.

[57] Stoka, V.; Turk, V.; Turk, B. Do lysosomes induce cell death? IUBMB Life 58:493494; 2006.

[58] Nilsson, E.; Ghassemifar, R.; Brunk, U. T. Lysosomal heterogeneity between and within cells with respect to resistance against oxidative stress. Histochem. J. 29:857-865; 1997.

[59] Barja, G. Rate of generation of oxidative stress-related damage and animal longevity. Free Radic. Biol. Med. 33:1167-1172; 2002.

[60] Sohal, R. S. Role of oxidative stress and protein oxidation in the aging process. Free Radic. Biol. Med. 33:37-44; 2002.

[61] Sheftel, A. D.; Zhang, A. S.; Brown, C.; Shirihai, O. S.; Ponka, P. Direct interorganellar transfer of iron from endosome to mitochondrion. Blood 110:125-132; 2007. 
[62] Antunes, F.; Cadenas, E.; Brunk, U. T. Apoptosis induced by exposure to a low steady-state concentration of $\mathrm{H}_{2} \mathrm{O}_{2}$ is a consequence of lysosomal rupture. Biochem. J. 356:549-555; 2001.

[63] Kurz, T.; Gustafsson, B.; Brunk, U. T. Intralysosomal iron chelation protects against oxidative stress-induced cellular damage. Febs J. 273:3106-3117; 2006.

[64] Li, W.; Yuan, X.; Nordgren, G.; Dalen, H.; Dubowchik, G. M.; Firestone, R. A.; Brunk, U. T. Induction of cell death by the lysosomotropic detergent MSDH. FEBS Lett. 470:35-39; 2000.

[65] Zhao, M.; Brunk, U. T.; Eaton, J. W. Delayed oxidant-induced cell death involves activation of phospholipase A2. FEBS Lett. 509:399-404; 2001.

[66] Yuan, X. M.; Li, W.; Dalen, H.; Lotem, J.; Kama, R.; Sachs, L.; Brunk, U. T. Lysosomal destabilization in p53-induced apoptosis. Proc. Natl. Acad. Sci. U. S. A. 99:6286$6291 ; 2002$.

[67] Timm, F. Histochemistry of heavy metals; the sulfide-silver procedure. Dtsch. Z. Gesamte Gerichtl. Med. 46:706-711; 1958.

[68] Nicoletti, I.; Migliorati, G.; Pagliacci, M. C.; Grignani, F.; Riccardi, C. A rapid and simple method for measuring thymocyte apoptosis by propidium iodide staining and flow cytometry. J. Immunol. Methods 139:271-279; 1991.

[69] Tanida, I.; Minematsu-Ikeguchi, N.; Ueno, T.; Kominami, E. Lysosomal turnover, but not a cellular level, of endogenous LC3 is a marker for autophagy. Autophagy 1:84-91; 2005. [70] Tenopoulou, M.; Kurz, T.; Doulias, P. T.; Galaris, D.; Brunk, U. T. Does the calceinAM method assay the total cellular 'labile iron pool' or only a fraction of it? Biochem. J. 403:261-266; 2007. 
[71] Terman, A.; Kurz, T.; Navratil, M.; Arriaga, E. A.; Brunk, U. T. Mitochondrial turnover and aging of long-lived postmitotic cells: the mitochondrial-lysosomal axis theory of aging. Antioxid. Redox Signal. 12:503-535; 2010.

[72] Kurz, T.; Terman, A.; Gustafsson, B.; Brunk, U. T. Lysosomes in iron metabolism, ageing and apoptosis. Histochem. Cell Biol. 129:389-406; 2008.

[73] Terman, A.; Gustafsson, B.; Brunk, U. T. Autophagy, organelles and ageing. $J$. Pathol. 211:134-143; 2007.

[74] Kurz, T.; Terman, A.; Gustafsson, B.; Brunk, U. T. Lysosomes and oxidative stress in aging and apoptosis. Biochim. Biophys. Acta 1780:1291-1303; 2008.

[75] Brunk, U. T.; Terman, A. The mitochondrial-lysosomal axis theory of aging: Accumulation of damaged mitochondria as a result of imperfect autophagocytosis. Eur. $J$. Biochem. 269:1996-2002; 2002.

[76] Jolly, R. D.; Douglas, B. V.; Davey, P. M.; Roiri, J. E. Lipofuscin in bovine muscle and brain: a model for studying age pigment. Gerontology 41:283-295; 1995.

[77] Kabeya, Y.; Mizushima, N.; Ueno, T.; Yamamoto, A.; Kirisako, T.; Noda, T.; Kominami, E.; Ohsumi, Y.; Yoshimori, T. LC3, a mammalian homologue of yeast Apg8p, is localized in autophagosome membranes after processing. EMBO J. 19:5720-5728; 2000.

[78] Turk, B.; Stoka, V.; Rozman-Pungercar, J.; Cirman, T.; Droga-Mazovec, G.; Oresic, K.; Turk, V. Apoptotic pathways: involvement of lysosomal proteases. Biol. Chem. 383:1035$1044 ; 2002$.

[79] Rock, K. L.; Gramm, C.; Rothstein, L.; Clark, K.; Stein, R.; Dick, L.; Hwang, D.; Goldberg, A. L. Inhibitors of the proteasome block the degradation of most cell proteins and the generation of peptides presented on MHC class I molecules. Cell 78:761-771; 1994.

[80] Brunk, U. T.; Neuzil, J.; Eaton, J. W. Lysosomal involvement in apoptosis. Redox Rep. 6:91-97; 2001. 
[81] Garner, B.; Li, W.; Roberg, K.; Brunk, U. T. On the cytoprotective role of ferritin in macrophages and its ability to enhance lysosomal stability. Free Radic. Res. 27:487-500; 1997.

[82] Baird, S. K.; Kurz, T.; Brunk, U. T. Metallothionein protects against oxidative stressinduced lysosomal destabilization. Biochem. J. 394:275-283; 2006.

[83] Kurz, T.; Brunk, U. T. Autophagy of HSP70 and chelation of lysosomal iron in a nonredox-active form. Autophagy 5:93-95; 2009.

[84] Balla, G.; Jacob, H. S.; Balla, J.; Rosenberg, M.; Nath, K.; Apple, F.; Eaton, J. W.; Vercellotti, G. M. Ferritin: a cytoprotective antioxidant strategem of endothelium. J. Biol. Chem. 267:18148-18153; 1992.

[85] Epsztejn, S.; Glickstein, H.; Picard, V.; Slotki, I. N.; Breuer, W.; Beaumont, C.; Cabantchik, Z. I. H-ferritin subunit overexpression in erythroid cells reduces the oxidative stress response and induces multidrug resistance properties. Blood 94:3593-3603; 1999.

[86] Orino, K.; Tsuji, Y.; Torti, F. M.; Torti, S. V. Adenovirus E1A blocks oxidantdependent ferritin induction and sensitizes cells to pro-oxidant cytotoxicity. FEBS Lett. 461:334-338; 1999.

[87] Tsuji, Y.; Ayaki, H.; Whitman, S. P.; Morrow, C. S.; Torti, S. V.; Torti, F. M. Coordinate transcriptional and translational regulation of ferritin in response to oxidative stress. Mol. Cell. Biol. 20:5818-5827; 2000.

[88] Bresgen, N.; Jaksch, H.; Lacher, H.; Ohlenschlager, I.; Uchida, K.; Eckl, P. M. Ironmediated oxidative stress plays an essential role in ferritin-induced cell death. Free Radic. Biol. Med. 48:1347-1357; 2010.

[89] Chen, W.; Li, N.; Chen, T.; Han, Y.; Li, C.; Wang, Y.; He, W.; Zhang, L.; Wan, T.; Cao, X. The lysosome-associated apoptosis-inducing protein containing the pleckstrin homology (PH) and FYVE domains (LAPF), representative of a novel family of PH and 
FYVE domain-containing proteins, induces caspase-independent apoptosis via the lysosomalmitochondrial pathway. J. Biol. Chem. 280:40985-40995; 2005.

[90] Li, N.; Zheng, Y.; Chen, W.; Wang, C.; Liu, X.; He, W.; Xu, H.; Cao, X. Adaptor protein LAPF recruits phosphorylated p53 to lysosomes and triggers lysosomal destabilization in apoptosis. Cancer Res. 67:11176-11185; 2007.

[91] Cozzi, A.; Corsi, B.; Levi, S.; Santambrogio, P.; Albertini, A.; Arosio, P. Overexpression of wild type and mutated human ferritin H-chain in HeLa cells: in vivo role of ferritin ferroxidase activity. J. Biol. Chem. 275:25122-25129; 2000.

[92] Cozzi, A.; Corsi, B.; Levi, S.; Santambrogio, P.; Biasiotto, G.; Arosio, P. Analysis of the biologic functions of $\mathrm{H}$ - and L-ferritins in HeLa cells by transfection with siRNAs and cDNAs: evidence for a proliferative role of L-ferritin. Blood 103:2377-2383; 2004.

[93] Kakhlon, O.; Gruenbaum, Y.; Cabantchik, Z. I. Repression of ferritin expression increases the labile iron pool, oxidative stress, and short-term growth of human erythroleukemia cells. Blood 97:2863-2871; 2001.

[94] Cozzi, A.; Rovelli, E.; Frizzale, G.; Campanella, A.; Amendola, M.; Arosio, P.; Levi, S. Oxidative stress and cell death in cells expressing L-ferritin variants causing neuroferritinopathy. Neurobiol. Dis. 37:77-85; 2010.

[95] Arosio, P.; Levi, S. Cytosolic and mitochondrial ferritins in the regulation of cellular iron homeostasis and oxidative damage. Biochim. Biophys. Acta 1800:783-792; 2010.

[96] Ferreira, C.; Bucchini, D.; Martin, M. E.; Levi, S.; Arosio, P.; Grandchamp, B.; Beaumont, C. Early embryonic lethality of $\mathrm{H}$ ferritin gene deletion in mice. J. Biol. Chem. 275:3021-3024; 2000 . 